\title{
Avaliação do uso tradicional e comércio de plantas medicinais e fitoterápicos no município de Resende, RJ: Uma contribuição para o desenvolvimento da Política Nacional de Plantas Medicinais e Fitoterápicos no Sul Fluminense
}

Evaluation of the traditional use and commerce of medicinal plants and phythoterapics in the municipality of Resende, RJ: A contribution to the development of the National Policy on Medicinal Plants and Phythoterapics in Sul Fluminense

Evaluación del uso y comercio tradicional de plantas medicinales y fitoterapéuticos en el municipio de Resende, RJ: Una contribución al desarrollo de la Política Nacional de las Plantas Medicinales y de los Fitoterapéuticos en Sul Fluminense

Recebido: 06/01/2022 | Revisado: 14/01/2022 | Aceito: 19/01/2022 | Publicado: 21/01/2022

\author{
Amanda Candido Custódio \\ ORCID: https://orcid.org/0000-0002-3449-4761 \\ Universidade do Estado do Rio de Janeiro, Brasil \\ E-mail:candidoc.amanda@gmail.com \\ Gabriela de Paula dos Santos Caetano \\ ORCID: https://orcid.org/0000-0002-0554-7385 \\ Universidade do Estado do Rio de Janeiro, Brasil \\ E-mail: gabrielasouzasantos11@gmail.com \\ Márcia Rosa de Almeida \\ ORCID: https://orcid.org/0000-0001-5700-4422 \\ Universidade do Estado do Rio de Janeiro, Brasil \\ E-mail: marcia.rosa@fat.uerj.br
}

\begin{abstract}
Resumo
Este trabalho visou realizar um levantamento etnobotânico das plantas comercializadas como medicinais e fitoterápicos no município de Resende, RJ. Para tanto, foram mapeados os principais tipos de comércio de plantas medicinais e fitoterápicos e as espécies vegetais comercializadas no município foram registradas. O uso tradicional relatado foi correlacionado com as propriedades biológicas dos metabólitos biossintetizados pelas espécies vegetais já descritas na literatura. $\mathrm{O}$ levantamento etnobotânico e a pesquisa acerca do uso de espécies vegetais e fitoterápicos no município revelou que $44 \%$ das espécies descritas na RENISUS são comercializadas nas feiras e ervanários visitados e, 77\% dessas espécies estão entre as mais consumidas. Foi possível observar que muitas das propriedades biológicas para as quais as espécies vegetais são tradicionalmente consumidas têm correlação com os metabólitos biossintetizados e comprovação descrita na literatura. Tais resultados podem auxiliar na implementação da Política Nacional de Plantas Medicinais e Fitoterápicos no munícipio e no Sul Fluminense, além de contribuir para o acesso seguro, o uso racional e sustentável da biodiversidade.
\end{abstract}

Palavras-chave: Plantas medicinais; Fitoterápicos; Política Nacional de Plantas Medicinais e Fitoterápicos.

\begin{abstract}
This work aimed to carry out an ethnobotanical survey of plants commercialized as medicinal and phytotherapics in the municipality of Resende, RJ. Therefore, the main types of commerce in medicinal plants and phytotherapics were mapped and the plant species commercialized in the municipality were registered. The traditional use reported was correlated with the biological properties of metabolites biosynthesized by plant species already described in the literature. The ethnobotanical survey and research on the use of plants species and phytotherapics in the city revealed that $44 \%$ of the species described in RENISUS are sold in the open-air market and herbal stores visited, and $77 \%$ of these species are among the most consumed. It was possible to observe that many of the biological properties for which plant species are traditionally consumed are correlated with biosynthesized metabolites and evidence described in the literature. These results can help implement the National Policy on Medicinal Plants and Phytotherapics in the municipality and in Sul Fluminense, in addition to contributing to safe access, rational and sustainable use of biodiversity.
\end{abstract}


Keywords: Medicinal plants; Phytotherapics; National Policy of Medicinal Plants and Phytotherapics medicines.

\section{Resumen}

Este trabajo tuvo como objetivo realizar un relevamiento etnobotánico de plantas comercializadas como medicinales y fitoterapéuticos en el municipio de Resende, RJ. Por lo tanto, se mapearon los principales tipos de comercio de plantas medicinales y fitoterapéuticos y se registraron las especies de plantas comercializadas en el municipio. El uso tradicional reportado se correlaciono con las propiedades biológicas de metabolitos biosintetizados por especies vegetales ya descritas en la literatura. El relevamiento etnobotánico y la investigación sobre el uso de especies vegetales y fitoterapéuticos en la ciudad revelaron que el $44 \%$ de las especies descritas en RENISUS se comercializan en las ferias y herbolarios visitadas, y el $77 \%$ de estas especies se encuentran entre las más consumidas. Se pudo observar que muchas de las propiedades biológicas por las que tradicionalmente se consumen especies vegetales están correlacionadas con metabolitos biosintetizados y evidencia descrita en la literatura. Estos resultados pueden ayudar a implementar la Política Nacional de las Plantas Medicinales y de los Fitoterapéuticos en el municipio y en Sul Fluminense, además de contribuir al acceso seguro, uso racional y sostenible de la biodiversidad.

Palabras clave: Plantas medicinales; Fitoterapéuticos; Política Nacional de las Plantas Medicinales y de los Fitoterapéuticos.

\section{Introdução}

A prática médica mais antiga e utilizada pela humanidade é o emprego de plantas com fins medicinais para tratamento, cura e prevenção de doenças. Assim, a fitoterapia tem papel de destaque na sociedade e vem recebendo amparo legal nos últimos anos.

Ao constatarem, em 1978, que 80\% da população dos países em desenvolvimento utilizavam práticas tradicionais nos cuidados básicos de saúde e $85 \%$ destes países utilizavam plantas ou preparações destas, a Organização Mundial de Saúde (OMS) e o Fundo das Nações Unidas para a Infância (UNICEF) realizaram, neste ano, a Conferência Internacional sobre Atenção Primária em Saúde em Alma-Ata, Genebra, para apresentar a necessidade de ação urgente dos governos, dos profissionais das áreas da saúde e da comunidade mundial. A OMS criou, ao final da década de 1970, o Programa de Medicina Tradicional que recomendava aos estados-membros o desenvolvimento de políticas públicas para facilitar a integração da medicina tradicional e da medicina complementar alternativa nos sistemas nacionais de atenção à saúde (Brasil, 2006a).

No período de 2002 a 2005, apenas 25 dos 191 estados-membros da OMS tinham desenvolvido uma política nacional de medicina tradicional como forma de fortalecer a atenção sanitária e de contribuir para a reforma do setor da saúde (Brasil, 2006a).

Somente em 2006, o Brasil lançou a Política Nacional de Plantas Medicinais e Fitoterápicos (PNPMF) (Brasil, 2006b) que garantia a melhoria do acesso da população aos medicamentos, à inclusão social e regional, ao desenvolvimento industrial e tecnológico, além do uso sustentável da biodiversidade brasileira e da valorização e preservação do conhecimento tradicional das comunidades tradicionais e indígenas (Brasil, 2006a) e, a Política de Práticas Integrativas e Complementares no Sistema Único de Saúde (SUS) (Brasil, 2006c) a fim de estimular e promover o acesso da população a serviços de oferta à saúde. Essa política propôs a inclusão de plantas medicinais e fitoterápicos, entre outras práticas médicas complementares, como opções terapêuticas no SUS (Brasil, 2006d).

Em 2008, foi criado o Programa Nacional de Plantas Medicinais e Fitoterápicos fundamentado na Política Nacional de Plantas Medicinais e Fitoterápicos (Brasil, 2008). Inserir plantas medicinais e fitoterápicos, além de serviços relacionados à fitoterapia no Sistema Único de Saúde (SUS), e promover e reconhecer as práticas populares e tradicionais de uso de plantas medicinais e remédios caseiros foram alguns dos objetivos do programa (Brasil, 2009). E em fevereiro de 2009, o Ministério da Saúde divulgou a Relação Nacional de Plantas Medicinais de Interesse ao SUS (RENISUS), a partir de uma listagem contendo 237 espécies vegetais já utilizadas nos serviços de saúde estaduais e municipais, com conhecimento tradicional e popular e, estudos químicos e farmacológicos conhecidos (Agência Saúde, 2009). Essa relação apresentava 71 espécies e 
objetivava orientar estudos e pesquisas para subsidiar a elaboração da lista de plantas medicinais e fitoterápicos a serem disponibilizados para uso da população, com segurança e eficácia (RENISUS, 2009).

Em 2013, foram inseridos 12 medicamentos fitoterápicos na Relação Nacional de Medicamentos Essenciais (RENAME) disponíveis no SUS. São eles: Alcachofra, aroeira, babosa, cáscara-sagrada, espinheira-santa, guaco, garra-dodiabo, hortelã, isoflavona-de-soja, plantago, salgueiro e unha-de-gato (Brasil, 2012; 2013a). E em 2014, a Agência Nacional de Vigilância Sanitária (ANVISA) regulamentou o registro de fitoterápicos e o registro e notificação de produtos tradicionais fitoterápicos (Brasil, 2014).

Segundo o Ministério da Saúde, entre 2013 e 2015, a procura por tratamentos à base de plantas medicinais e fitoterápicos cresceu 161\%. Em 2015, cerca de 16.000 pessoas procuraram alguma farmácia de atenção básica para receber insumos de origem natural. $\mathrm{O}$ guaco, a espinheira-santa e a isoflavona-de-soja são os fitoterápicos mais utilizados na rede pública, indicados para o tratamento de problemas respiratórios, gastrite e úlcera e sintomas do climatério, respectivamente (Brasil, 2016).

A OMS define planta medicinal como todo e qualquer vegetal que possui, em um ou mais órgãos, substâncias que podem ser utilizadas com fins terapêuticos ou que sejam precursores de fármacos semi-sintéticos (World Health Organization, 1998). Essas possuem a capacidade de diminuir a ação ou prover a cura de doenças, sendo tradicionalmente utilizadas por grupos ou comunidades. Em definição mais simples, a ANVISA indica que a planta medicinal é a espécie vegetal, cultivada ou não, utilizada com propósitos terapêuticos (Brasil, 2013b).

Já os fitoterápicos são medicamentos obtidos com emprego exclusivo de matérias-primas ativas vegetais, cuja eficácia e segurança são validadas por meio de levantamentos etnofarmacológicos, de utilização, documentações tecno-científicas ou evidências clínicas (Brasil, 2010). A ANVISA define medicamentos fitoterápicos como aqueles cuja segurança e eficácia estão baseadas em evidências clínicas, e produtos tradicionais fitoterápicos como aqueles cuja segurança e efetividade estão fundamentadas na tradicionalidade de uso por período mínimo de 30 anos, concebidos para serem utilizados sem necessidade de supervisão médica, em condições clínicas brandas (Brasil, 2014).

As propriedades biológicas das espécies vegetais utilizadas como medicinais dependem da classe química dos metabólitos biossintetizados. Os metabólitos primários são as substâncias essenciais ao crescimento e desenvolvimento das espécies vegetais, como carboidratos, lipídios e proteínas. Esses metabólitos são fornecedores de matéria-prima e de energia para formação de outros metabólitos, denominados secundários ou especiais. Estes são responsáveis pela existência e preservação das espécies vegetais em seu ambiente e, frequentemente apresentam propriedades farmacológicas (Kreis, et al., 2017; Santos, 2004). Entre os metabólitos secundários estão os taninos, lignanas, ligninas, cumarinas, antraquinonas, flavonoides, terpenos, esterois, acetogeninas e os alcaloides.

O resgate da etnobotânica, a divulgação do comércio de espécies vegetais e fitoterápicos em diferentes regiões e comunidades brasileiras, além de seus constituintes químicos e ação biológica comprovada, podem auxiliar na implementação da Política Nacional de Plantas Medicinais e Fitoterápicos, especialmente no SUS.

A cidade de Resende, localizada no sul do Estado do Rio de Janeiro, apresenta duas unidades de conservação para a proteção de biomas ameaçados, como o Parque Estadual da Pedra Selada (Instituto Estadual do Ambiente, 2021), localizado na Serra da Mantiqueira, que abrange parte dos municípios de Resende (78,4\%) e Itatiaia (21,6\%), e o Parque Nacional do Itatiaia (Brasil, 2021), também situado na Serra da Mantiqueira, que abrange os municípios de Resende e Itatiaia, no Rio de Janeiro e Bocaina de Minas e Itamonte no Estado de Minas Gerais, onde fica aproximadamente 60\% de seu território.

$\mathrm{O}$ resgate da etnobotânica e o uso tradicional associado ao conhecimento científico contribuirão para evidenciar as atividades farmacológicas das espécies vegetais e difundir seu uso nos sistemas púbicos de saúde. Assim, este trabalho teve como objetivos mapear os principais tipos de comércio de plantas medicinais e fitoterápicos, registrar as principais espécies 
vegetais comercializadas no município de Resende e correlacionar o saber popular com o científico a partir das propriedades biológicas de seus constituintes químicos já descritas na literatura. Dessa maneira, contribuir para o desenvolvimento da Política Nacional de Plantas Medicinais e Fitoterápicos (PNPMF) no Sul Fluminense, para o acesso seguro e o uso racional de espécies vegetais, além de promover o uso sustentável da biodiversidade.

\section{Metodologia}

A área de estudo, Resende, localizado no sul do Estado do Rio de Janeiro, é um município de 1.099,336 Km² , com população estimada de 133.244 habitantes, sendo considerado o vigésimo terceiro município mais populoso do estado, segundo os dados do Instituto Brasileiro de Geografia e Estatística (IBGE). O município faz divisa com os estados de Minas Gerais e São Paulo e apresenta cerca de 43\% de área urbana arborizada (Instituto Brasileiro de Geografia e Estatística, 2017).

Para coleta de dados sobre o uso de plantas medicinais e fitoterápicos comercializados em Resende, foi feito um mapeamento das principais feiras livres e ervanários da região central da cidade e proximidades, bem como nos principais acessos à cidade, conforme apresentado no Quadro 1. Em seguida, as feiras livres e os estabelecimentos comerciais foram visitados e as espécies vegetais e os fitoterápicos comercializados foram catalogados. Foram utilizados questionários semiestruturados com os feirantes e comerciantes para avaliação dos principais produtos comercializados e seus usos tradicionais.

O uso tradicional de plantas empregadas como medicinais foi correlacionado com estudos biológicos já realizados, através de pesquisa bibliográfica em diferentes bases de dados. Foram descritas as principais partes utilizadas e as classes de metabólitos biossintetizados para as espécies vegetais comercializadas no município, responsáveis por suas principais propriedades biológicas (Quadro 2). As espécies vegetais comercializadas foram comparadas às descritas na RENISUS.

\section{Resultados e Discussão}

Para a coleta de dados sobre o comércio de plantas medicinais e fitoterápicos foram selecionadas as principais feiras livres e ervanários localizados na região central da cidade, em bairros próximos a essa região e em bairro de acesso à cidade, conforme descrito no Quadro 1 e Figura 1. Foram visitadas três feiras livres e quatro ervanários no período de maio a agosto de 2019.

Quadro 1: Localização das feiras livres e ervanários visitados para coleta de dados sobre o comércio de plantas medicinais e fitoterápicos em Resende, RJ.

\begin{tabular}{|c|c|c|}
\hline $\begin{array}{c}\text { Tipo de } \\
\text { Comércio }\end{array}$ & Identificação & Localização \\
\hline \multirow{3}{*}{ Feira livre (F) } & 1 & Região central da cidade \\
\cline { 2 - 3 } & 2 & Próximo à região central da cidade \\
\cline { 2 - 3 } & 3 & Bairro de acesso à cidade \\
\hline \multirow{2}{*}{ Ervanário (E) } & 1 & Região central da cidade \\
\cline { 2 - 3 } & 2 & Próximo à região central da cidade \\
\cline { 2 - 3 } & 3 & Próximo à região central da cidade \\
\cline { 2 - 3 } & 4 & Próximo à região central da cidade \\
\hline
\end{tabular}

Fonte: Autores. 
Research, Society and Development, v. 11, n. 2, e15211225423, 2022

(CC BY 4.0) | ISSN 2525-3409 | DOI: http://dx.doi.org/10.33448/rsd-v11i2.25423

Figura 1: Localização das Feiras livres (F) e Ervanários (E) visitados para coleta de dados sobre o comércio de plantas medicinais e fitoterápicos em Resende, RJ.

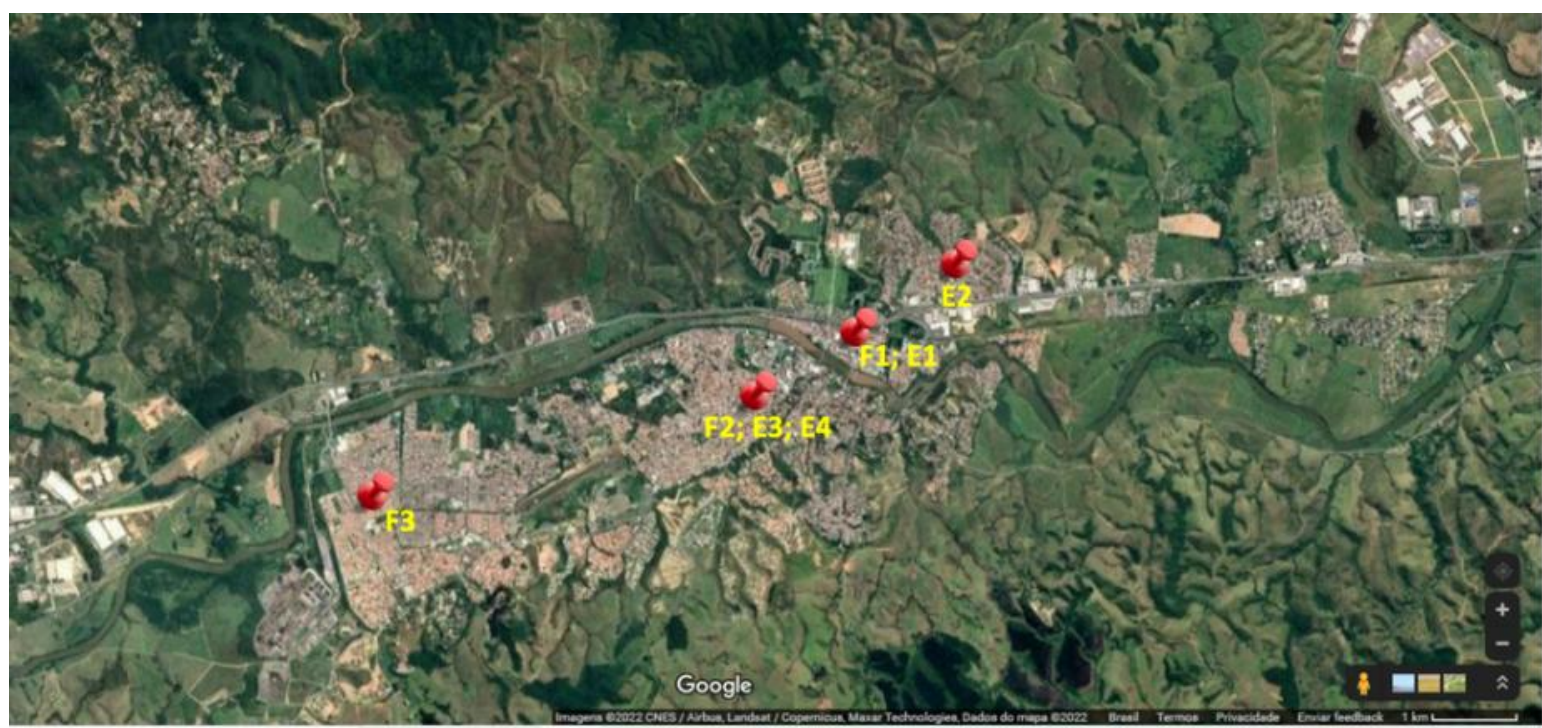

Legenda: Feiras livres 1 (F1); 2 (F2); 3 (F3) e 4 (F4); Ervanários 1 (E1); 2 (E2); 3 (E3) e 4 (E4).

Fonte: Adapatado de Google Maps (2022).

Foi observado o comércio de plantas medicinas nas Feiras livres 2 e 3. Já na Feira livre 1, localizada na região central da cidade, foi registrado apenas a venda de fitoterápicos.

Em todos os ervanários visitados foi observado maior número de plantas medicinais disponíveis para venda quando comparado aos fitoterápicos, como apresentado na Figura 2. As plantas medicinais são frequentemente adquiridas por consumidores porque são tradicionalmente conhecidas. Em um dos ervanários, um dos mais antigos da cidade, foram registrados 98 diferentes espécies de plantas medicinais e 34 fitoterápicos (Ervanário 4) (Figura 2).

Figura 2: Distribuição de plantas medicinais e fitoterápicos comercializados em feiras livres e ervanários da cidade de Resende.

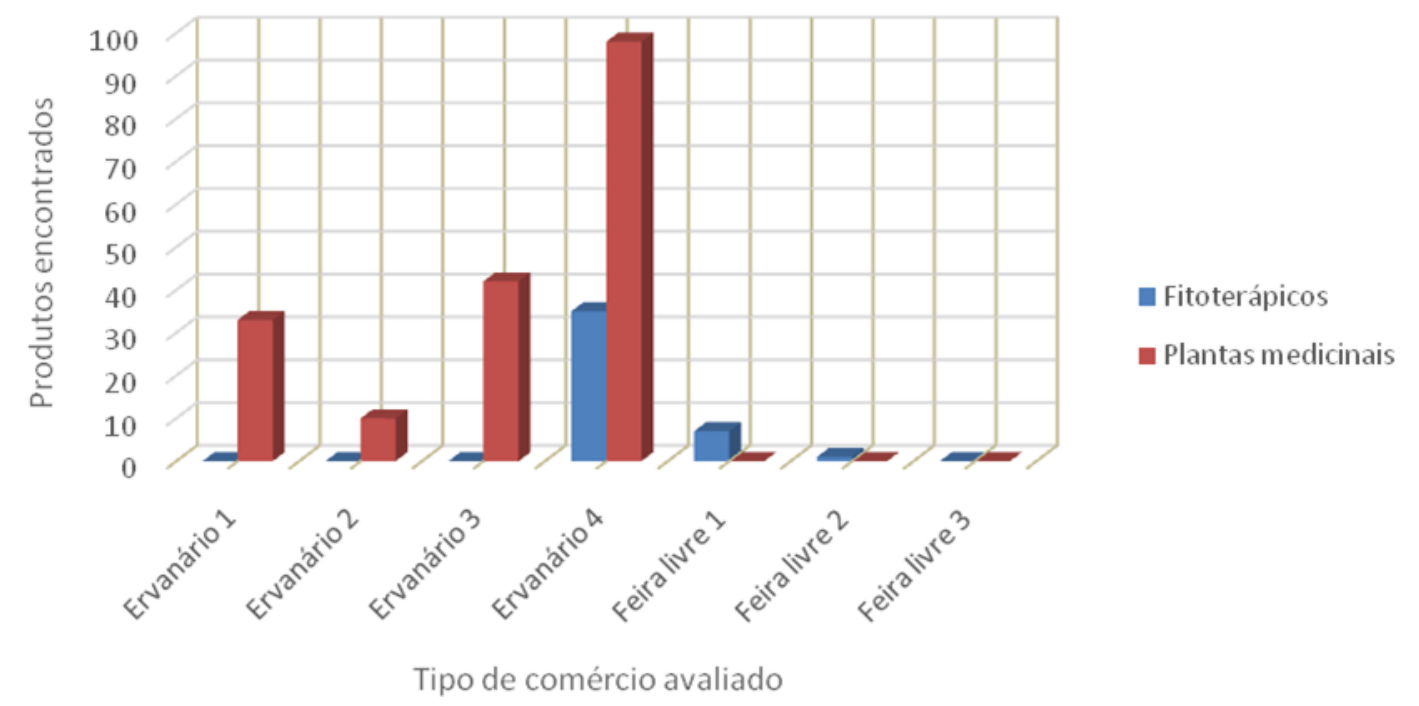

Fonte: Autores. 
Ao todo foram registradas 72 diferentes espécies vegetais e 43 fitoterápicos comercializados para fins medicinais em Resende, a partir das feiras livres e ervanários visitados. As principais espécies vegetais comercializadas como medicinais, a parte utilizada, a classe de seus constituintes químicos, bem como a ação farmacológica descrita na literatura são apresentadas na Tabela 1 .

Tabela 1. Principais espécies vegetais comercializadas no município e classe de metabólitos responsáveis por suas propriedades biológicas descritas na literatura.

\begin{tabular}{|c|c|c|c|c|c|}
\hline $\begin{array}{l}\text { Nome } \\
\text { popular }\end{array}$ & Nome científico & $\begin{array}{l}\text { Principal } \\
\text { parte } \\
\text { utilizada }\end{array}$ & $\begin{array}{l}\text { Classe de } \\
\text { metabólitos }\end{array}$ & Propriedades biológicas & Referências \\
\hline Alecrim & $\begin{array}{l}\text { Rosmarinus } \\
\text { officinalis }\end{array}$ & $\begin{array}{l}\text { Folhas e } \\
\text { flores }\end{array}$ & $\begin{array}{l}\text { Substâncias fenólicas } \\
\text { (ácido rosmarínico e } \\
\text { flavonoides) }\end{array}$ & $\begin{array}{l}\text { antioxidante, anti-inflamatório, } \\
\text { hepatoprotetor, anticâncer, } \\
\text { antiasmático, antiespasmódico, } \\
\text { anti-isquêmico, antiulcerativo, } \\
\text { diminuição do risco de } \\
\text { aterosclerose }\end{array}$ & $\begin{array}{l}\text { Erkan, et al., 2008; } \\
\text { Al-Sereiti, et al., } \\
1999\end{array}$ \\
\hline Alfafa & Medicago sativa & Partes áreas & $\begin{array}{l}\text { saponinas, cumarinas, } \\
\text { esterois, flavonoides e } \\
\text { outras substâncias } \\
\text { fenólicas }\end{array}$ & $\begin{array}{l}\text { Efeito no sistema nervoso } \\
\text { central e no sistema } \\
\text { cardiovascular, antioxidante, } \\
\text { ansiolítico }\end{array}$ & $\begin{array}{l}\text { Bora \& Sharma, } \\
\text { 2012; Bora \& } \\
\text { Sharma, 2010; Rana, } \\
\text { et al., } 2010\end{array}$ \\
\hline Alfazema & $\begin{array}{l}\text { Lavandula } \\
\text { angustifólia }\end{array}$ & $\begin{array}{l}\text { Partes } \\
\text { aéreas }\end{array}$ & $\begin{array}{l}\text { Terpenos (linalol, } \\
\text { acetato de linalila, } \\
\text { cineol, cânfora e } \beta \text { - } \\
\text { cimeno) }\end{array}$ & $\begin{array}{l}\text { antioxidante, tratamento de } \\
\text { rinite, anti-inflamatório, } \\
\text { analgésico, sedativo, tratamento } \\
\text { da doença de Parkinson e } \\
\text { Alzheimer }\end{array}$ & $\begin{array}{l}\text { Soheili \& Salami, } \\
\text { 2019; Sheikhani, et } \\
\text { al., 2017; Hui, et al., } \\
\text { 2010; Hajhashemi, et } \\
\text { al., } 2003\end{array}$ \\
\hline Algodão & Gossypium spp & $\begin{array}{l}\text { Planta } \\
\text { inteira }\end{array}$ & Flavonoides & antimicrobiano, antimalarial & Lima, et al., 2021 \\
\hline Amora & Morus nigra & $\begin{array}{l}\text { Folhas e } \\
\text { frutos }\end{array}$ & $\begin{array}{l}\text { Flavonoides, } \\
\text { antocianinas e } \\
\text { derivados }\end{array}$ & $\begin{array}{l}\text { antioxidante, imunomodulador, } \\
\text { anti-inflamatório, } \\
\text { antinociceptivo, } \\
\text { antiespasmódico, tratamento de } \\
\text { sintomas da menopausa }\end{array}$ & $\begin{array}{l}\text { Rodrigues, et al., } \\
\text { 2021; Budiman, et } \\
\text { al., 2019; Rodrigues, } \\
\text { et al., 2019; } \\
\text { Zoofishan, et al., } \\
2019\end{array}$ \\
\hline $\begin{array}{l}\text { Anis } \\
\text { estrelado }\end{array}$ & Illicium verum & $\begin{array}{l}\text { Folhas, } \\
\text { frutos e } \\
\text { sementes }\end{array}$ & $\begin{array}{l}\text { Flavonoides, lignanas, } \\
\text { terpenos }\end{array}$ & $\begin{array}{l}\text { antiviral, ansiolítico, efeito no } \\
\text { sistema nervoso central }\end{array}$ & $\begin{array}{l}\text { Patra, et al., 2020; } \\
\text { Chouksey, et al., } \\
2020\end{array}$ \\
\hline Arnica & $\begin{array}{l}\text { Arnica montana, } \\
\text { Lychnophora spp. }\end{array}$ & $\begin{array}{l}\text { Folhas, } \\
\text { flores e } \\
\text { rizomas }\end{array}$ & $\begin{array}{l}\text { Flavonoides, lignanas, } \\
\text { terpenos }\end{array}$ & $\begin{array}{l}\text { anti-inflamatório, analgésico, } \\
\text { antipirético, cicatrizante (pós- } \\
\text { operatório), ansiolítico }\end{array}$ & $\begin{array}{l}\text { Athayde, et al., 2021; } \\
\text { Iannitti, et al., 2016; } \\
\text { Borsato, et al., 2000; } \\
\text { Ahmad, et al., 2013 }\end{array}$ \\
\hline Aroeira & $\begin{array}{l}\text { Schinus } \\
\text { terebinthifolius }\end{array}$ & $\begin{array}{l}\text { Folhas, } \\
\text { frutos e } \\
\text { cascas }\end{array}$ & $\begin{array}{l}\text { Flavonoides, } \\
\text { terpenoides }\end{array}$ & $\begin{array}{l}\text { antioxidante, antigenotóxico, } \\
\text { antidiabético, anti-hemolítico, } \\
\text { anti-inflamatório, } \\
\text { antinociceptivo, antibacteriano }\end{array}$ & $\begin{array}{l}\text { Feriani, et al., 2020; } \\
\text { Uliana, et al., } 2016\end{array}$ \\
\hline Arruda & Ruta graveolens & $\begin{array}{l}\text { Partes } \\
\text { aéreas }\end{array}$ & $\begin{array}{l}\text { Alcaloides, cumarinas, } \\
\text { flavonoides }\end{array}$ & $\begin{array}{l}\text { anti-inflamatório, analgésico, } \\
\text { antiandrogênico,anti- } \\
\text { hiperglicêmico, anti- } \\
\text { hiperlipidêmico, anti-gota, } \\
\text { anticâncer, fotoprotetor }\end{array}$ & $\begin{array}{l}\text { Cefali, et al., 2019; } \\
\text { Asgarpanah \& } \\
\text { Khoshkam, } 2012\end{array}$ \\
\hline Assa peixe & $\begin{array}{l}\text { Vernonia } \\
\text { polyanthes }\end{array}$ & Folhas & $\begin{array}{l}\text { cumarinas, triterpenos, } \\
\text { flavonoides, taninos } \\
\text { condensados, taninos } \\
\text { hidrolisáveis }\end{array}$ & $\begin{array}{l}\text { anti-inflamatório, } \\
\text { antinociceptivo }\end{array}$ & $\begin{array}{l}\text { Oliveira, et al., 2019; } \\
\text { Temponi, et al., } 2012\end{array}$ \\
\hline
\end{tabular}




$\begin{array}{clll}\text { Banchá } & \text { Camellia sinensis } & \begin{array}{l}\text { Folhas e } \\ \text { flores }\end{array} & \begin{array}{l}\text { Flavonoides, alcaloides. } \\ \text { terpenos }\end{array} \\ & & \\ \text { Barbatimão } & \begin{array}{l}\text { Stryphnodendron } \\ \text { adstringens }\end{array} & \begin{array}{l}\text { Cascas do } \\ \text { caule e } \\ \text { folhas }\end{array} & \begin{array}{l}\text { Taninos, flavonoides, } \\ \text { flavonois, alcaloides, } \\ \text { terpenos, estilbenos, } \\ \text { esteroides }\end{array} \\ & & & \\ & \text { Arctium lappa } & \begin{array}{l}\text { Folhas, } \\ \text { flores e } \\ \text { raízes }\end{array} & \begin{array}{l}\text { taninos, lignanas } \\ \text { (arctigenina, arctiina), } \\ \text { terpenos, fitoesteróis }\end{array} \\ & & & \end{array}$

Boldo do Peumus boldus Folhas Chile

\begin{tabular}{|c|c|c|}
\hline Bugre & Casearia sylvestris & $\begin{array}{l}\text { Folhas e } \\
\text { cascas d } \\
\text { caule }\end{array}$ \\
\hline $\begin{array}{l}\text { Cabelo de } \\
\text { milho }\end{array}$ & Zea mays & Estigma \\
\hline Calêndula & $\begin{array}{l}\text { Calendula } \\
\text { officinalis }\end{array}$ & Flores \\
\hline Camomila & $\begin{array}{l}\text { Matricaria } \\
\text { chamomilla }\end{array}$ & $\begin{array}{l}\text { Partes } \\
\text { aéreas }\end{array}$ \\
\hline Cana do brejo & Costus spicatus & Folhas \\
\hline $\begin{array}{l}\text { Canela-de- } \\
\text { velho }\end{array}$ & Miconia albicans & Folhas \\
\hline $\begin{array}{l}\text { Capim } \\
\text { cidreira }\end{array}$ & $\begin{array}{l}\text { Cymbopogon } \\
\text { citratus }\end{array}$ & Folhas \\
\hline
\end{tabular}

Carobinha Jacaranda

Flavonoides, alcaloides, taninos, terpenos, polifenóis (catequinas)

Alcaloides, esteróis, saponinas, taninos, flavonoides, terpenos carotenóides

Flavonoides saponinas, alcaloides, triterpenos

flavonoides, saponinas, taninos anticâncer, antitumoral,
antioxidante, anti-inflamatório, antimutagênico, antidiabético, hipoglicemiante, antiviral, antimicrobiano, antiparasitário

antiparasitário, antifúngico, antiviral, antioxidante, anticâncer, antimicrobiano, antisséptico, anti-inflamatório, antinociceptivo, antiulcerativo, cicatrizante

antialérgico, anti-

hiperglicêmico, anti-

inflamatório, antioxidante, antidiabético, anti-herpes, esquistossomicida

antioxidante, anti-inflamatório, antimicrobiano, quimioprotetor

anti-inflamatório, anti-H. pylori, antihiperalgésico, leishmanicida

Saeed, et al., 2017;

Senger, et al., 2010

Nascimento, et al., 2021; Lima, et al, 2016

Cui, et al., 2022; Annunziata, et al., 2019; Dias, et al., 2017; MaghsoumiNorouzabad, et al., 2016; Knipping, et al., 2008

Otero, et al., 2022; Ferrante, et al., 2020; Fernández, et al., 2009; Quezada, et al., 2006;

Heymanns, et al., 2021; Pascoalino, et al., 2020; Spósito, et al., 2019; Antinarelli, et al., 2015

analgésico, anti-inflamatório, antioxidante, diurético

Pinheiro, et al., 2011; Owoyele, et al., 2010; El-Ghorab, et al., 2007;

Tung, et al., 2019; Jan, et al., 2017; Parente, et al., 2012 flavonoides, cumarinas, inflamatório, antifadiga

antifúngico, antiestreptocócico, antioxidante, antimicrobiano, sedativo, calmante

Seyedjavadi, et al., 2019; Owlia, et al. 2007; Roby, et al., 2013; Avallone, et al., 2000

nefroprotetor, antilítico, hipolipemiante, antioxidante

antiartrítico, antioxidante, antiinflamatório

antidiabético (diabetes mellitus), antimicrobiano, ansiolítico, anticâncer anticonvulsivante

Moreno, et al., 2021; Lorençone, et al., 2021

Quintans-Junior, et al., 2020; Lima, et al., 2020

Hacke, et al., 2021; Elekofehinti, et al., 2020; Boeira, et al., 2020; Hacke, et al., 2020; Trang, et al., 2020

cicatrizante, antioxidante
Serra, et al., 2020;

Carvalho, et al., 2009 


\begin{tabular}{|c|c|c|c|c|c|}
\hline $\begin{array}{l}\text { Carqueja } \\
\text { amarga }\end{array}$ & Baccharis trimera & $\begin{array}{l}\text { Partes } \\
\text { aéreas }\end{array}$ & $\begin{array}{l}\text { Flavonoides } \\
\text { (hispidulina), } \\
\text { diterpenos, lactonas } \\
\text { diterpências }\end{array}$ & $\begin{array}{l}\text { hepatoprotetor, antioxidante, } \\
\text { antiulccerativo }\end{array}$ & $\begin{array}{l}\text { Bueno, et al., 2021; } \\
\text { Barbosa, et al., 2020 }\end{array}$ \\
\hline Cavalinha & Equisetum arvense & $\begin{array}{l}\text { Partes } \\
\text { aéreas }\end{array}$ & $\begin{array}{l}\text { Saponinas, flavonoides } \\
\text { (luteolina), alcaloides, } \\
\text { taninos, fitoesterois, } \\
\text { triterpenos }\end{array}$ & $\begin{array}{l}\text { antioxidante, anticâncer, anti- } \\
\text { inflamatório, diurético }\end{array}$ & $\begin{array}{l}\text { Boeing, et al., 2021; } \\
\text { Bhat, et al., } 2020\end{array}$ \\
\hline $\begin{array}{l}\text { Centella } \\
\text { asiática }\end{array}$ & Centella asiatica & $\begin{array}{l}\text { Partes } \\
\text { aéreas }\end{array}$ & $\begin{array}{l}\text { Saponinas Triterpênicas } \\
\text { (ácido asiático) }\end{array}$ & $\begin{array}{l}\text { antidiabético, } \\
\text { anti-inflamatório, antiacneico, } \\
\text { cicatrizante }\end{array}$ & $\begin{array}{l}\text { Swapna, et al., 2019; } \\
\text { Shen, et al., 2019; } \\
\text { Yao, et al., } 2017\end{array}$ \\
\hline $\begin{array}{l}\text { Chapéu de } \\
\text { couro }\end{array}$ & $\begin{array}{l}\text { Echinodorus } \\
\text { macrophyllus }\end{array}$ & Folhas & $\begin{array}{l}\text { saponinas, alcaloides, } \\
\text { quinonas, flavonas, } \\
\text { flavonois, xantonas, } \\
\text { triterpenoides e } \\
\text { esteroides }\end{array}$ & $\begin{array}{l}\text { nefroprotetor, diurético, } \\
\text { renoprotetor, } \\
\text { anti-inflamatório }\end{array}$ & $\begin{array}{l}\text { Silva, et al., 2016; } \\
\text { Nascimento, et al., } \\
\text { 2014; Portella, et al., } \\
2012\end{array}$ \\
\hline Dente de leão & $\begin{array}{l}\text { Taraxacum } \\
\text { officinale }\end{array}$ & $\begin{array}{l}\text { Raízes e } \\
\text { folhas }\end{array}$ & $\begin{array}{l}\text { Fitoesteróis, lactonas } \\
\text { sesquiterpênicas, } \\
\text { flavonoides, ácidos } \\
\text { fenólicos }\end{array}$ & $\begin{array}{l}\text { antidiabético, } \\
\text { hipoglicêmico, hepatoprotetor }\end{array}$ & $\begin{array}{l}\text { Savych, et al., 2021; } \\
\text { Koubaa, et al., } 2020\end{array}$ \\
\hline Erva baleeira & Cordia verbenacea & $\begin{array}{l}\text { Partes } \\
\text { aéreas }\end{array}$ & $\begin{array}{l}\text { Flavonoides, } \\
\text { terpenoides }\end{array}$ & $\begin{array}{l}\text { antioxidante, fotoprotetor, anti- } \\
\text { inflamatório }\end{array}$ & $\begin{array}{l}\text { Melo, et al., 2021; } \\
\text { Bodini, et al., 2020 }\end{array}$ \\
\hline Erva grossa & $\begin{array}{l}\text { Elephanto } \\
\text { pusscaber }\end{array}$ & $\begin{array}{l}\text { Folhas e } \\
\text { raízes }\end{array}$ & $\begin{array}{l}\text { Lactonas } \\
\text { sesquiterpênica, } \\
\text { triterpenos, esteroides } \\
\text { flavonoides }\end{array}$ & anti-inflamatório, antidiabético & $\begin{array}{l}\text { Han, et al., 2020; } \\
\text { Daisy, et al., } 2007\end{array}$ \\
\hline $\begin{array}{l}\text { Espinheira } \\
\text { santa }\end{array}$ & Maytenus ilicifolia & Folhas & Terpenos & $\begin{array}{l}\text { anti-hiperglicêmico, digestivo, } \\
\text { cicatrizante, anti-inflamatório, } \\
\text { protetor da mucosa gástrica }\end{array}$ & $\begin{array}{l}\text { Schindler, et al., } \\
\text { 2021; Santos- } \\
\text { Oliveira, et al., } 2009\end{array}$ \\
\hline $\begin{array}{l}\text { Espinheiro } \\
\text { branco }\end{array}$ & $\begin{array}{l}\text { Crataegus } \\
\text { oxycantha }\end{array}$ & $\begin{array}{l}\text { Folhas e } \\
\text { flores }\end{array}$ & $\begin{array}{l}\text { Proantocianidinas, } \\
\text { polifenóis }\end{array}$ & neuroprotetor, imunomodulador & $\begin{array}{l}\text { Khazaei, et al., 2020; } \\
\text { Elango \& Devaraj, } \\
2010\end{array}$ \\
\hline Guaco & Mikania glomerata & Folhas & $\begin{array}{l}\text { Cumarinas, } \\
\text { lactonassesquiterpênica } \\
\text { s, fitoesteróis, terpenos, } \\
\text { flavonoides. }\end{array}$ & $\begin{array}{l}\text { anti-alérgico, antiasmático, } \\
\text { broncodilatador, antiviral, } \\
\text { antimicrobiano }\end{array}$ & Santana, et al., 2014 \\
\hline Moringa & Moringa oleifera & $\begin{array}{l}\text { Folhas, } \\
\text { sementes e } \\
\text { raízes }\end{array}$ & $\begin{array}{l}\text { Carotenoides, } \\
\text { substâncias fenólicas } \\
\text { (ácido clorogênico), } \\
\text { flavonoides (rutina) }\end{array}$ & $\begin{array}{l}\text { antioxidante, anti-inflamatório, } \\
\text { antitumoral, antidiabético }\end{array}$ & Silva, et al., 2021 \\
\hline Mulungu & Erythrina verna & $\begin{array}{l}\text { Cascas do } \\
\text { caule e } \\
\text { folhas }\end{array}$ & $\begin{array}{l}\text { Alcaloides (11-alfa- } \\
\text { hidroxieritravina) }\end{array}$ & $\begin{array}{l}\text { ansiolítico, analgésico, } \\
\text { anticonvulsivante, anti- } \\
\text { inflamatório, antimicrobiano }\end{array}$ & $\begin{array}{l}\text { Rambo, et al., 2019a; } \\
\text { 2019b }\end{array}$ \\
\hline Oliveira & Olea europaea & $\begin{array}{l}\text { Folhas e } \\
\text { frutos }\end{array}$ & $\begin{array}{l}\text { Substâncias fenólicas } \\
\text { (oleuropeína e 3- } \\
\text { hidroxitirosol) }\end{array}$ & $\begin{array}{l}\text { antimicrobiano, antioxidante, } \\
\text { diminuição de desconforto } \\
\text { gastrointestinal }\end{array}$ & $\begin{array}{l}\text { Malfa, et al., 2021; } \\
\text { Antunes, et al., } 2020\end{array}$ \\
\hline Pariparoba & $\begin{array}{l}\text { Pothomorphe } \\
\text { umbellata }\end{array}$ & $\begin{array}{l}\text { Folhas, } \\
\text { hastes e } \\
\text { raízes }\end{array}$ & $\begin{array}{l}\text { Fenilpropanoides, } \\
\text { sesquiterpenos, } \\
\text { flavonoides, ligininas }\end{array}$ & $\begin{array}{l}\text { antioxidante, analgésico, anti- } \\
\text { inflamatório, anticâncer, } \\
\text { fotoprotetor }\end{array}$ & $\begin{array}{l}\text { Iwamoto, et al., 2015; } \\
\text { Noriega, et al., } 2008\end{array}$ \\
\hline Pata de vaca & Bauhinia forficata & Folhas & $\begin{array}{l}\text { Flavonoides } \\
\text { glicosilados } \\
\text { (kaempferitrina) }\end{array}$ & $\begin{array}{l}\text { antidiarreico, hipoglicemiante, } \\
\text { diurético, antioxidante, } \\
\text { antimicrobiano }\end{array}$ & $\begin{array}{l}\text { Tang, et al., 2019; } \\
\text { Silva-López \& } \\
\text { Santos, } 2015\end{array}$ \\
\hline
\end{tabular}




\begin{tabular}{|c|c|c|c|c|c|}
\hline Pau-pereira & $\begin{array}{l}\text { Geissospermum } \\
\text { vellosii }\end{array}$ & $\begin{array}{l}\text { Cascas do } \\
\text { caule }\end{array}$ & $\begin{array}{l}\text { Alcaloides } \\
\text { (geissospermina, } \\
\text { flavopereirina) }\end{array}$ & $\begin{array}{l}\text { febrífugo, antimalarial, anti- } \\
\text { inflamátório, antinociceptivo }\end{array}$ & $\begin{array}{l}\text { Almeida, et al., 2017; } \\
\text { Lima, et al., 2016; } \\
\text { Almeida, et al., 2012; } \\
\text { Almeida, et al., 2009 }\end{array}$ \\
\hline Pau-tenente & Quassia amara & $\begin{array}{l}\text { Folhas, } \\
\text { cascas do } \\
\text { caule e } \\
\text { raízes }\end{array}$ & $\begin{array}{l}\text { Alcaloides, } \\
\text { quassinoides e terpenos }\end{array}$ & $\begin{array}{l}\text { antitumoral, antimalarial, } \\
\text { fagoinibidor, inseticida, } \\
\text { antiparasitário, antiulcerogênico }\end{array}$ & $\begin{array}{l}\text { Raji \& Oloyede, } \\
2012 \text {; Almeida, et al., } \\
2007\end{array}$ \\
\hline Picão & Bidens pilosa & $\begin{array}{l}\text { Planta } \\
\text { inteira }\end{array}$ & Flavonoides & $\begin{array}{l}\text { antitumoral, anti-inflamatório, } \\
\text { antiviral, imunomodulador, } \\
\text { antidiabético, anti-hipertensivo, } \\
\text { antimicrobiano }\end{array}$ & $\begin{array}{l}\text { Bartolome, et al., } \\
2013\end{array}$ \\
\hline Poejo & Mentha pulegium & $\begin{array}{l}\text { Partes } \\
\text { aéreas }\end{array}$ & $\begin{array}{l}\text { Terpenos (pulegona, } p \text { - } \\
\text { mentona e piperitenona) }\end{array}$ & $\begin{array}{l}\text { antioxidante, anti- } \\
\text { toxoplasmático, } \\
\text { anticolinesterásico }\end{array}$ & $\begin{array}{l}\text { Bektasevic, et al., } \\
2021 \text {; Rahimi, et al., } \\
2020\end{array}$ \\
\hline $\begin{array}{l}\text { Porangaba, } \\
\text { chá de bugre }\end{array}$ & Cordia ecalyculata & $\begin{array}{l}\text { Folhas e } \\
\text { ramos }\end{array}$ & $\begin{array}{l}\text { Flavonoides, taninos, } \\
\text { saponinas, alcaloides, } \\
\text { terpenos, estereoides }\end{array}$ & antiviral, hipolipidêmico & $\begin{array}{l}\text { Alexandre, et al., } \\
2021\end{array}$ \\
\hline Quebra pedra & Phyllanthus niruri & $\begin{array}{l}\text { Planta } \\
\text { inteira }\end{array}$ & $\begin{array}{l}\text { Lignanas (filantina), } \\
\text { Compostos fenólicos } \\
\text { (ácido gálico), } \\
\text { flavonoides (quercetina) }\end{array}$ & $\begin{array}{l}\text { diurético, controle da } \\
\text { urolitíase, hepatoprotetor, } \\
\text { antiaterosclerótico }\end{array}$ & $\begin{array}{l}\text { Al Zarzour, et al., } \\
2017 \text {; Cruces, et al., } \\
2013\end{array}$ \\
\hline Salvia & Salvia officinalis & $\begin{array}{l}\text { Folhas e } \\
\text { flores }\end{array}$ & $\begin{array}{l}\text { Terpenos (1,8-cineol, } \\
\text { cânfora, alfa-tujona, } \\
\text { borneol e viridiflorol) }\end{array}$ & $\begin{array}{l}\text { anti-inflamatório, } \\
\text { hipoglicemiante, antioxidante, } \\
\text { antidiabético }\end{array}$ & $\begin{array}{l}\text { Ghowsi, et al., 2020; } \\
\text { Li, et al., 2019; } \\
\text { Pereira, et al., } 2018\end{array}$ \\
\hline Sene & Senna alexandrina & $\begin{array}{l}\text { Folhas e } \\
\text { frutos }\end{array}$ & $\begin{array}{l}\text { Senosídeo A e B } \\
\text { (derivados de } \\
\text { antraquinona) }\end{array}$ & $\begin{array}{l}\text { antioxidante, antimicrobiano, } \\
\text { antimutagênico, anti- } \\
\text { inflamatório, laxante }\end{array}$ & Farid, et al., 2020 \\
\hline Sete sangrias & $\begin{array}{l}\text { Cuphea } \\
\text { carthagenensis }\end{array}$ & $\begin{array}{l}\text { Planta } \\
\text { inteira }\end{array}$ & $\begin{array}{l}\text { Flavonoides, taninos, } \\
\text { alcaloides, estereoides, } \\
\text { triterpenos }\end{array}$ & $\begin{array}{l}\text { diurético, anti-hipertensivo, } \\
\text { vasodilatador, antioxidante } \\
\text { antiaterosclerótico }\end{array}$ & $\begin{array}{l}\text { Santos, et al., 2020; } \\
\text { Otenio et al., 2020; } \\
\text { Schaedler, et al., } \\
\text { 2018; Begmeier, et } \\
\quad \text { al., } 2014\end{array}$ \\
\hline Unha de gato & Uncaria tomentosa & $\begin{array}{l}\text { Folhas, } \\
\text { cascas do } \\
\text { caule e } \\
\text { raízes }\end{array}$ & $\begin{array}{l}\text { Flavonoides, alcaloides, } \\
\text { terpenos, cumarinas }\end{array}$ & $\begin{array}{l}\text { antioxidante, anti-inflamatório, } \\
\text { antineoplásico, antimicrobiano, } \\
\text { antiviral, imunomodulador, } \\
\text { anti-Alzheimer }\end{array}$ & Batiha, et al., 2020 \\
\hline Uva ursi & $\begin{array}{l}\text { Arctostaphylos uva- } \\
\text { ursi }\end{array}$ & Folhas & $\begin{array}{l}\text { Taninos, glicosídeos } \\
\text { fenólicos (arbutina) }\end{array}$ & $\begin{array}{l}\text { antibacteriano, diurético, } \\
\text { adstringente }\end{array}$ & Das, 2020 \\
\hline Uxi amarelo & Endopleura uchi & $\begin{array}{l}\text { Cascas do } \\
\text { caule e fruto }\end{array}$ & $\begin{array}{l}\text { Terpenos, taninos, } \\
\text { flavonoides, } \\
\text { carotenoides }\end{array}$ & $\begin{array}{l}\text { antidiabético, antimicrobiano, } \\
\text { anti-inflamatório, antioxidante, } \\
\text { anticolinesterásico }\end{array}$ & Oliveira, et al., 2021 \\
\hline
\end{tabular}

Fonte: Autores.

As espécies comercializadas foram comparadas com as espécies disponibilizadas na RENISUS. Foi possível observar que cerca de 44\% das espécies descritas na RENISUS são comercializadas nas feiras e ervanários visitados em Resende. E 77\% dessas espécies estão entre as mais consumidas, segundo os feirantes e comerciantes dos estabelecimentos visitados. Fato que pode auxiliar no desenvolvimento da Política Nacional de Plantas Medicinais e Fitoterápicos (PNPMF) no município. Poucos trabalhos acerca do uso tradicional e comércio de espécies vegetais foram realizados em cidades próximas à Resende (Silva, et al., 2021; Sombra, 2016; Martinazzo, et al., 2013; Gonçalves, et al., 2011; Parente, Rosa, 2001), mas não há registro na literatura sobre o uso tradicional e o comércio de espécies vegetais no município. Ao que tudo indica, o Sul Fluminense carece 
de estudos para auxiliar na implementação dessa Política de âmbito nacional e, para divulgação e disponibilização de plantas medicinais e fitoterápicos no SUS.

Diferentes espécies vegetais pertencentes à família Asteraceae são conhecidas popularmente e utilizadas como "arnica" no Brasil, devido às propriedades farmacológicas e metabólitos produzidos semelhantes à Arnica montana, espécie nativa da Europa, considerada a arnica verdadeira. Calea uniflora Less; Chaptalia nutans (L.), Lychnophora ericoides Mart., L. pinaster Mart., L. salicifolia Mart., Porophyllum ruderale (Jacq.) Cass., Pseudobrickellia brasiliensis (Spreng.) R. M. King \& H. Rob, Solidago chilensis Meyen e Sphagneticola trilobata (L.) Pruski são algumas das espécies denominadas e consumidas como "arnicas" no Brasil. A arnica verdadeira e as espécies conhecidas como arnica são tradicionalmente utilizadas como antiinflamatório, anestésico e cicatrizante (Athayde, et al., 2021; Iannitti, et al., 2016; Ahmad, et al., 2013; Borsato, et al., 2000). De acordo com Athayde e colaboradores (2021), as espécies S. trilobata, S. chilensis e L. pinaster apresentam composição química semelhante à composição da A. montana, quando comparada às demais espécies. Registros indicam a ocorrência natural das espécies Sphagneticola trilobata (L.) (Mondin, 2020) e S. chilensis (Valverde, et al., 2012) em todos os estados da região sudeste do país, já a espécie L. pinaster ocorre preferencialmente em Minas Gerais (CNCFlora, 2012).

O comércio de arnica foi observado nas Feiras livres 2 e 3 e a procedência não foi informada, entretanto, os feirantes recomendavam o preparo de infusão em álcool, utilizando todas as partes da planta, para aplicação em machucados ou contusões. As folhas de espécies de arnica são ricas em flavonoides e lactonas sesquiterpênicas, estas são responsáveis por sua ação anti-inflamatória (Athayde, et al., 2021), e as raízes são ricas em lignanas, responsáveis pela atividade analgésica, antiinflamatória e antipirética (Borsato, et al., 2000). Também foi observado o comércio de gel de arnica no ervanário 4, e a espécie utilizada informada no rótulo foi A. montana (Quadro 4).

A RDC 26/2014 da ANVISA (Brasil, 2014) e o Formulário Nacional de Fitoterápicos da Farmacopéia Brasileira (Brasil, 2021) alertam apenas para o uso tópico da arnica. A ingestão não é recomendada devido a toxicidade de diferentes espécies conhecidas como arnica (Oliveira, et al., 2021; Ferreira, et al., 2014).

O chá verde e o banchá foram encontrados na Feira livre 1 e foi esclarecido pelo feirante que trata-se da mesma espécie vegetal, Camellia sinensis. O chá verde é preparado com as folhas jovens e tenras dessa espécie, já o banchá é preparado a partir das folhas mais velhas e rasteiras. O preparo tradicional e a matéria-prima utilizada são confirmadas por Matsubara \& Rodriguez-Amaya (2006). As folhas de Camellia sinensis são ricas em flavonoides, principalmente as catequinas, sendo a majoritária a epigalocatequina galato, correspondendo de 50 a $60 \%$ das catequinas encontradas nas folhas (Senger, et al., 2010). A diferença da matéria-prima utilizada no preparo de chás, folhas novas ou velhas, reflete no sabor, cor e nas propriedades farmacológicas devido as concentrações de catequinas (Matsubara\& Rodriguez-Amaya, 2006). Estudos comprovaram a ação anti-inflamatória, antitumoral, antiaterogênica, hipoglicemiante e no controle do peso das catequinas produzidas por Camellia sinensis (Senger, et al., 2010).

As principais espécies vegetais e os fitoterápicos comercializados como medicinais na região central da cidade são apresentados nos Quadros 2 e 3. 
Quadro 2: Espécies vegetais mais vendidas no Ervanário 1 (Região central da Cidade).

\begin{tabular}{|c|c|}
\hline Nomenclatura popular & Uso tradicional \\
\hline Cavalinha & Emagrecimento \\
Porangaba & \\
Chá verde & Combate à insônia \\
\hline Mulungu & \\
Camomila & \\
Alecrim & Combate sintomas do climatério \\
\hline Amora miura & Tratamento de cálculo renal \\
\hline Uva ursi & \\
\hline Quebra-pedra & Tratamento de dores estomacais \\
Cabelo de milho & Tratamento para engravidar ("Chá da gravidez"), \\
\hline Espinheira Santa & tratamento de ovários micropolicísticos \\
\hline Unha de gato & Uxi amarelo \\
\hline
\end{tabular}

Fonte: Autores.

A cavalinha, de nome científico Equisetum arvense, foi encontrada nos Ervanários 1 e 3, sendo indicada para o emagrecimento. A literatura indica o emprego dessa espécie para impedir a retenção de líquido pelo organismo, o que pode ocasionar a perda de peso. O efeito diurético da espécie vegetal se justifica pela presença de flavonoides e sais de potássio (Boeing, et al., 2021). As partes aéreas da planta também apresentam alcaloides e taninos. Alguns estudos apontam seu uso para o tratamento de doenças reumáticas, cálculos renais, infecções no trato urinário e ação anti-hemorrágica, anti-inflamatória e remineralizante (Bhat, et al., 2020; Boeing, et al., 2021).

O chá da porangaba (Cordia ecalyculata Vell.), chá de bugre ou café do mato, é utilizado popularmente para a perda de peso, entretanto, alguns pesquisadores descrevem a ineficácia da espécie para redução do peso corporal ou no combate a obesidade (Alexandre, et al., 2021; Silva, et al., 2010).

Para combater a insônia são comumente comercializados e tradicionalmente consumidos na cidade, os chás de mulungu, camomila e alecrim, como mostra o Quadro 3. Estudos confirmam a atividade ansiolítica para o mulungu (Rambo, et al., 2019a; 2019b) e para o alecrim (Pimentel, 2021) e, propriedades sedativas para a camomila (Avallone, et al., 2000).

As cascas, folhas e flores de mulungu, Erythina velutina, são utilizadas também para o tratamento da asma, tosses de fundo nervoso, como febrífugo e calmante. Seus principais metabólitos secundários são os alcaloides, flavonoides e isoflavonoides. Destes, os alcaloides eritravina e 11-hidróxi-eritravina possuem atividade ansiolítica e são, provavelmente, responsáveis no combate à insônia (Rambo, et al., 2019a; 2019b).

Já a camomila, Matricaria chamomilla, é popularmente conhecida por seu efeito calmante (Avallone, et al., 2000). A partir das flores secas ou capítulos florais secos ocorre a extração de flavonoides e óleo volátil que são os responsáveis por suas propriedades terapêuticas, em especial a ação ansiolítica. A espécie produz flavonoides, sesquiterpenos e cumarinas. Estudos sugerem que um ou mais de seus flavonoides produzidos podem gerar a atividade ansiolítica e a espécie pode ser empregada como antidepressivo (Santos, et al., 2019; Keefea, et al, 2016). Já o sesquiterpeno alfa-bisabolol confere propriedades antiinflamatória e analgésica à camomila (Santos, et al., 2019).

A espécie Morus nigra conhecida como amora negra é tradicionalmente utilizada para combater sintomas do climatério provocados por alterações hormonais nas mulheres durante a transição da menopausa. Suores noturnos, palpitações, dores de 
cabeça, alterações no metabolismo ósseo e manifestações cardiovasculares e psicológicas, como depressão, irritabilidade, fadiga e perda da libido são os sintomas mais comuns relatados (Rodrigues, et al., 2021). Essa espécie produz diferentes substâncias fenólicas, como flavonoides, que podem atuar como fitoestrógenos e aliviar os sintomas do climatério. Estudos etnofarmacológicos conduzidos no Brasil confirmaram o uso efetivo da Morus nigra para o tratamento de sintomas do climatério (Rodrigues, et al., 2021).

A literatura descreve o uso de Quebra-pedra, Phyllanthus niruri, como terapia no controle de urolitíase e, destaca sua eficácia na prevenção de urólitos (Cruces, et al., 2013), já as espécies Cabelo de milho (Zea mays) e Uva ursi (Arctostaphylos uva-ursi) apresentam propriedades diuréticas (Pinheiro, et al., 2011; Das, 2020). Assim, os estudos apresentados confirmam as propriedades biológicas que justificam o uso tradicional dessas espécies.

Para o tratamento de dores estomacais, a população resendense consome o chá da espécie Espinheira santa que indicou ser digestivo, anti-inflamatório e protetor da mucosa gástrica (Schindler, et al., 2021; Santos-Oliveira, et al., 2009). Já as espécies Unha de gato e Uxi amarelo são utilizadas para o tratamento de doenças do aparelho reprodutor feminino, com o objetivo, muitas vezes, de engravidar, são conhecidas popularmente e comercializadas como "chá de gravidez".

Segundo Revilla (2002), o chá obtido das cascas de Uxi amarelo é um potente anti-inflamatório indicado no combate às inflamações uterinas, miomas e ovários policísticos, já o extrato de unha de gato demonstrou ser promissor no tratamento da endometriose (Neto, et al., 2011).

A partir do levantamento etnobotânico das espécies mais vendidas no ervanário 1, localizado na região central, descritas no Quadro 3, pode-se observar que o comércio e o uso tradicional da maioria das espécies, pela população resendense, está de acordo com a literatura, segundo a pesquisa bibliográfica e a classe de metabólitos apresentadas no Quadro 2. O que possibilita a ampla divulgação de uso tradicional dessas espécies vegetais para auxiliar na implementação da fitoterapia no serviço de saúde do município e fornecimento gratuito de espécies vegetais à população, alcançando dessa forma alguns dos objetivos descritos na PNPMF.

$\mathrm{Na}$ região central da cidade foi observado o comércio de fitoterápicos indicados, principalmente, para tratamento de dores em geral e problemas respiratórios (Quadro 3).

Quadro 3: Fitoterápicos comercializados na Feira livre 1 (Região central da Cidade).

\begin{tabular}{|c|c|c|c|}
\hline Fitoterápicos & Composição & Apresentação & Uso Tradicional \\
\hline $\mathrm{A}$ & Canela-de-Velho (Miconia albicans) & Xarope & $\begin{array}{c}\text { Tratamento de artrite, artrose, dores } \\
\text { articulares em geral }\end{array}$ \\
\hline B & $\begin{array}{c}\text { Espinheira Santa, Alcachofra do Norte, } \\
\text { Artemisia, Carqueja amarga,Castanha da índia, } \\
\text { Cavalinha, Chapéu de Couro, Ipê roxo, } \\
\text { Jurubeba e Salsa Parilha }\end{array}$ & Xarope & $\begin{array}{c}\text { Tratamento de úlceras, gastrite, dores } \\
\text { estomacais, cálculo renal, } \\
\text { diabetes e redução do colesterol }\end{array}$ \\
\hline C & $\begin{array}{c}\text { Óleo de buriti, Caraguatá, Cabreúva, Cravo, } \\
\text { Canela, Cebola branca, Cidreira,Carambá, } \\
\text { Carapiá, Alcaçuz, Alecrim, Angico, Assa- } \\
\text { peixe, Alfavaca, Erva de Santa Maria, } \\
\text { Fedegoso, Jatobá,Hortelã, Poejo, Mangerona, } \\
\text { Mucambê, Papachona, Velame do Campo, mel } \\
\text { deJatá, óleo de Copaíba e Babosa }\end{array}$ & Xarope & $\begin{array}{c}\text { Tratamento de bronquite, asma, } \\
\text { gripe, chiado no peito, inflamações } \\
\text { de garganta, tosse e infecções } \\
\text { pulmonares }\end{array}$ \\
\hline $\mathrm{D}$ & Hortelã-pimenta (Mentha piperita) & Óleo & $\begin{array}{c}\text { Tratamento de rinite, sinusite, mau } \\
\text { hálito, fadiga e dores musculares }\end{array}$ \\
\hline $\mathrm{E}$ & Menta (Mentha spicata) & Óleo & $\begin{array}{c}\text { Tratamento de dores musculares, } \\
\text { dores de cabeça, cólicas abdominais, } \\
\text { sinusite, micoses, impigens e frieiras }\end{array}$ \\
\hline $\mathrm{F}$ & Arnica (Arnica montana) & Gel & $\begin{array}{c}\text { Tratamento de dores articulares, } \\
\text { reumáticas e contusões }\end{array}$ \\
\hline
\end{tabular}




\begin{tabular}{|c|c|c|c|}
\hline $\mathrm{G}$ & $\begin{array}{l}\text { Erva de Santa Maria, Barbatimão, Copaíba, } \\
\text { Arnica, Andiroba, Alecrim, Aroeira, Babosa, } \\
\text { Confrei, Centelha asiática, Castanha da índia, } \\
\text { Castanha do Pará, Arruda, Malva, Noni }\end{array}$ & Gel & $\begin{array}{l}\text { Alívio de dores nas pernas e costas, } \\
\text { tratamento de dores em geral }\end{array}$ \\
\hline
\end{tabular}

Fonte: Autores.

Foi observado o comércio de fitoterápicos simples, produzido com apenas uma espécie vegetal, como a Canela-develho (Miconia albicans) e a Hortelã-pimenta (Mentha piperita), e fitoterápicos compostos, aqueles que incluem em sua composição mais de uma espécie vegetal. Constatou-se que todos os fitoterápicos comercializados na região central da cidade são industrializados, diferente da maioria dos fitoterápicos comercializados no ervanário 4 , que são preparados de forma artesanal (Brasil, 2018).

\section{Conclusão}

A presente pesquisa identificou o comércio e consumo de plantas medicinais e fitoterápicos em diferentes bairros, escolhidos estrategicamente, na região central e proximidades, do município de Resende no Estado do Rio de Janeiro. O levantamento etnobotânico e a pesquisa acerca do uso de espécies vegetais e fitoterápicos no município revelou que $44 \%$ das espécies descritas na RENISUS são comercializadas nas feiras e ervanários visitados e, 77\% dessas espécies estão entre as mais consumidas. Foi possível observar que muitas das propriedades biológicas para as quais as espécies vegetais são tradicionalmente consumidas têm correlação com os metabólitos biossintetizados e comprovação científica descrita na literatura. Tais resultados podem contribuir para a implementação da fitoterapia no SUS e desenvolvimento de políticas públicas para o estímulo da produção de insumos farmacêuticos vegetais de elevado valor agregado, bem como a adoção de estratégias para o fortalecimento de sua cadeia produtiva. Além dessas contribuições, esse estudo poderá colaborar com o desenvolvimento da Política Nacional de Plantas Medicinais e Fitoterápicos no Sul Fluminense.

\section{Agradecimentos}

À Pró-Reitoria de Extensão e Cultura da Universidade do Estado do Rio de Janeiro pela bolsa concedida ao projeto e a todos os feirantes e comerciantes do município de Resende que colaboraram com a pesquisa.

\section{Referências}

Agência Saúde. (2009). MS elabora Relação de Plantas Medicinais de Interesse ao SUS. Disponível em: http://bvsms.saude.gov.br/bvs/sus/pdf/marco/ms_relacao_plantas_medicinais_sus_0603.pdf. Acessoem 5 dez. 2021.

Ahmad, M.; Saeed, F., MehJabeen \& Jahan N. (2013). Neuro-Pharmacological and analgesic effects or arnica Montana extract. International Journal of Pharmacy and Pharmaceutical Sciences, 5(4), 590-593.

Alexandre, K. P.; Yasuda, F. S.; Marques, L. C.; Gonçalves C. P.; Veiga, R. S.; Oliveira, S. M. L. \& Marcucci, M. C. (2021). Guaçatonga (Casearia sylvestris SW) e porangaba (Cordiasalicifolia ou Cordiaecalyculata Vell/Boraginaceae) possuem ação no emagrecimento? Brazilian Journal of Natural Sciences, 3(1), $3-15$.

Almeida, M. M. B.; Ariaga, A. M. C.; Santos, A. K. L.; Lemos, T. L. G.; Braz-Filho, R. \& Vieira, I. J. C. (2007). Ocorrência e atividade biológica de quassinóides da última década. Química Nova, 30(4), 1-17.

Almeida, M. R.; Lima J. A.; Santos, N. P \& Pinto, A. C. (2009). Pereirina: o primeiro alcaloide isolado no Brasil? Revista Braileira de Farmacognosia, 19(4), 942-952.

Almeida, M. R.; Martinez, S. T. \& Pinto, A. C. (2017). Química de Produtos Naturais: Plantas que testemunham histórias. Revista Virtual de Química, 9(3), 1117-1153.

Almeida, M. R.; Silva, A. E. S.; Braga, A. O.; Braga, J. M. A.; Tamaio, N. \& Pinto, A. C. (2012). Anatomical description, alkaloid content and quality controlof the bark of Pau-pereira (Geissospermum laeve, Apocynaceae). Journal of Medicinal Plants Research, 6(10), 1866-1872. 
Al-Sereiti, M. R.; Abu-Amer, K. M. \& Sena, P. (1999). Pharmacology of rosemary (Rosmarinus oificinalis Linn.) and its therapeutic potentials. Indian Journal of Experimental Biology, 37, 124-130.

Al Zarzour, R. A.; Ahmad, M.; Asmawi, M. Z.; Kaur, G.; Saeed, M. A. A.; AL-Mansoub, M. A.; Saghir, S. A. M.; Usman, N. S.; Al-Dulaimi, D. W. \& Yam, M. F. (2017). Phyllanthus niruri standardized extract alleviates the progression of non-alcoholic fatty liver disease and decreases atherosclerotic risk in Sprague-Dawley rats.Nutrients, 9(7), 766.

Annunziata, G.; Barrea, L.; Ciampaglia, R.; Cicala, C.; Arnone, A.; Savastano, S.; Nabavi, S. M.; Tenore, G. C. \& Novellino, E. (2019). Arctium lappa contributes to the management of type 2 diabetes mellitus by regulating glucose homeostasis and improving oxidative stress: a critical review of in vitro and in vivo animal: Based studies. Phytotherapy Research, 33(9), 2213-2220.

Antinarelli, L. M. R.; Pinto, N. C.; Scio, E. \& Coimbra, E. S. (2015). Antileishmanial activity of some Brazilian plants, with particular reference to Casearia sylvestris. Anais da Acaemia Brasileira de Ciênias, 87(2), 733-742.

Antunes, B.F.; Otero, D. M.; Oliveira, F. M.; Jacques, A. C. \& Gandra, E. A. (2020). Antioxidant and antimicrobial activity of olive trees cultivated in the CampanhaGaúcha region. Brazilian Journal of Development, 6(4), 21791-21805.

Asgarpanah, J. \& Khoshkam, R. (2012). Phytochemistry and pharmacological properties of Ruta graveolens L. Journal of Medicinal Plants Research, 6(23), 3942-3949.

Athayde, A. E.; Araujo, C. E. S.; Sandjo, L. P. \& Biavatti, M. W. (2021). Metabolomic analysis among ten tradicional “Arnica” (Asteraceae) from Brazil. Journal of Ethnopharmacology, 265, 113149.

Avallone, R.; Zanoli, P.; Puia, G.; Kleinschnitz, M.; Schreier, O. \& Baraldi, M. (2000). Pharmacological profile of Apigenin, a flavonoid isolated from Matricaria chamomilla. Biochemical Pharmacology, 59(11),1387-1394.

Barbosa, R. J.; Silva, G. R.; Cola, I. M.; Kuchler, J. C.; Coelho, N.; Barboza, L. N.; Menetrier, J. V.; Souza, R.; Zonta, F. N.; Froehlich, D. L.; Jacomassi, E.; Soares, A. A.; Velasques, L. G.; Veiga, A. A., Souza, L. M.; Lovato, E. C. W.; Ribeiro-Paes, J. T.; Gasparotto Junior, A.; Acco, A. \& Lívero, F. A. R. (2020). Promising therapeutic use of Baccharis trimera (less.) DC. as a natural hepatoprotective agent again sthepaticlesions that are caused by multiple risk factors. Journal of Ethnopharmacology, 254,112729.

Bartolome, A. P.; Villaseñor, I. M. \& Yang, W. C. (2013). Bidens pilosa L. (Asteraceae): botanical properties, traditional uses, phytochemistry and pharmacology. Evidence-Based Complemenary and Alternative Medicine, 2013, 1-51.

Batiha, G. E. S.; Beshbishy, A. M.; Wasef, L.; Elewa, Y. H. A.; Abd El-Hack, M. E.; Taha, A. E.; Al-Sagheer, A. A.; Devkota, H. P. \& Tufarelli, V. (2020). Uncaria tomentosa (Willd. ex Schult.) DC.: A Review on chemical constituents and biological activities. Applied Sciences, 10(8), $2668-2679$.

Begmeier, D.; Berres, P. H. D.; Filippi, D.; Bilibio, D.; Bettiol, V. R. \& Priamo, W. L. (2014). Extraction of total polyphenols from hibiscus (Hibiscus sabdariffa L.) and wax weed/‘sete-sangrias' (Cuphea carthagenensis) and evaluation of their antioxidant potential. Acta Scientiarum. Technology, 36(3), 545551.

Bektasevic, M.; Politeo, O. \& Carev, I. (2021). Comparative study of chemical composition, cholinesterase inhibition and antioxidant potential of Mentha pulegium L. essential oil. Chemistry \& Biodiversity, 18(3), e2000935.

Bhat, A. A.; Ahamad, B.; Rehman, U. M. \& Ahmad, P. (2020). Impact of ethanolic extract of Equisetum arvense (EA1) on pancreatic carcinoma AsPC-1 cells. Saudi Journal of Biological Sciences, 27(5), 1260-1264.

Bodini, R. B.; Pugine, S. M. P.; Melo, M. P. \& Carvalho, R. A. (2020). Antioxidant and anti-inflammatory properties of orally disintegrating films based on starch and hydroxypropyl methylcellulose incorporated with Cordia verbenacea (ervabaleeira) extract. International Journal of Biological Macromolecules, $159,714-724$

Boeing, T.; Moreno, K. G. T.; Gasparotto Junior, A.; Mota da Silva, L. \& Souza, P. G. (2021). Phytochemistry and pharmacology of the genus Equisetum (Equisetaceae): A narrative review of the species with therapeutic potential for kidney diseases.Evidence-Based Complemenary and Alternative Medicine, 2021, 1-17.

Boeira, C. P.; Piovesan, N.; Flores, D. C. B.; Soquetta, M. B.; Lucas, B. N.; Heck, R. T.; Alves, J. S.; Campagnol, P. C. B.; Santos, D.; Flores, E. M. M.; Rosa, C. S. \& Terra, N. N. (2020). Phytochemical characterization and antimicrobial activity of Cymbopogon citratus extract for application as natural antioxidant in fresh sausage. Food Chemistry, 319, 126553.

Bora, K. S. \& Sharma, A. (2012). Evaluation of anxiolytic effect of Medicago sativa in mice. Pharmaceutical Biology, 50(7), 878-882.

Bora, K. S. \& Sharma, A. (2011). Phytochemical and pharmacological potential of Medicago sativa: a review. Pharmaceutical Biology, 49(2), 211-220.

Borsato, M. L. C.; Grael, C. F.; Souza, G. E. \& Lopes, N. P. (2000). Analgesic activity of the lignans from Lychnophoraericoides. Phytochemistry, 55(7), 809813.

Brasil. (2021). Parque Estadual do Itatiaia. Ministério do Meio Ambiente. ICMBio, 2021. Disponível em: http://www.icmbio.gov.br/parnaitatiaia/. Acesso em 5 dez. 2021.

Brasil. (2006a). Política Nacional de Plantas Medicinais e Fitoterápicos. Brasilia: Ministério da Saúde.

Brasil. (2006b). Decreto $n^{\circ}$ 5.813, de 22 de junho de 2006. Ministério da Saúde; 2006. Disponível em: http://www.planalto.gov.br/ccivil_03/_ato20042006/2006/decreto/d5813.htm. 
Brasil. (2006c). Portaria n $\mathrm{n}^{\mathrm{o}}$ 971, de 3 de maio de 2006. Ministério da Saúde; 2006. Disponível em: https://bvsms.saude.gov.br/bvs/saudelegis/gm/2006/prt0971_03_05_2006.html.

Brasil. (2006d). Política de Práticas Integrativas e Complementares no SUS - PNPIC-SUS. Brasilia: Ministério da Saúde.

Brasil. (2008). Portaria Interministerial $\mathrm{n}^{\mathrm{o}}$ 2960, de 9 de dezembro de 2008. Ministério da Saúde; 2008. Disponível em: https://bvsms.saude.gov.br/bvs/saudelegis/gm/2008/pri2960_09_12_2008.html.

Brasil. (2009). Programa Nacional de Plantas Medicinais e Fitoterápicos. Brasilia: Ministério da Saúde.

Brasil. (2010). Resolução RDC Nº 14, de 31 de março de 2010. Ministério da Saúde. Agência Nacional de Vigilância Sanitária; 2010. Disponível em: https://bvsms.saude.gov.br/bvs/saudelegis/anvisa/2010/rdc0014_31_03_2010.html.

Brasil. (2012). Portaria $\mathrm{n}^{\mathrm{o}}$ 533, de 28 de março de 2012. Ministério da Saúde; 2012. Disponível em: https://bvsms.saude.gov.br/bvs/saudelegis/gm/2012/prt0533_28_03_2012.html.

Brasil. (2013a). Relação Nacional de Medicamentos Essenciais: RENAME 2013. Brasilia: Ministério da Saúde.

Brasil. (2013b). Resolução RDC Nº. 14, de 14 de março de 2013. Ministério da Saúde, Agência Nacional de Vigilância Sanitária; 2013. Disponível em: https://bvsms.saude.gov.br/bvs/saudelegis/anvisa/2013/rdc0014_14_03_2013.pdf.

Brasil. (2014). Resolução RDC nº. 26, de 13 de maio de 2014. Ministério da Saúde, Agência Nacional de Vigilância Sanitária; 2014. Disponível em: https://bvsms.saude.gov.br/bvs/saudelegis/anvisa/2014/rdc0026_13_05_2014.pdf.

Brasil. (2016). Uso de fitoterápicos e plantas medicinais cresce no SUS. Ministério da Saúde. Disponível em: https://www.saude.gov.br/noticias/agenciasaude/24205-uso-de-fitoterapicos-e-plantas-medicinais-cresce-no-sus. Acesso em 5 dez. 2021.

Brasil. (2018). Consolidado de normas de registro e notificações de fitoterápicos. Brasília: Agência Nacional de Vigilância Sanitária.

Brasil. (2021). Formulário de Fitoterápicos. Farmacopéia Brasileira. Brasília: Agência Nacional de Vigilância Sanitária.

Budiman, A.; Praditasari, A.; Rahayu, D. \& Aulifa D. (2019). Formulation of antioxidant gel from black mulberry fruit extract (Morus nigra L.). Journal of Pharmacy and Bioallied Sciences, 11(3), 216-22.

Bueno, G.; Rico, S. L. C.; Périco, L. L.; Ohara, R.; Rodrigues, V. P.; Emílio-Silva, M. T.; Assunção, R.; Machado da Rocha, L. R.; Nunes, D. S.; Besten, M. A.; Heiden, G.; Lima Camargo, A. C.; Justulin, L. A. \& Hiruma-Lima, C. A. (2021). The essential oil from Baccharis trimera (Less.) DC improves gastric ulcer healing in rats through modulation of VEGF and MMP-2 activity. Journal of Ethnopharmacology, 271, 113832-41.

Carvalho, C. A.; Lourenço, M. V.; Bertoni, B. W.; França, S. C.; Pereira, P. S.; Fachin, A. L. \& Pereira, A. M. S. (2009). Atividade antioxidante de Jacaranda decurrens Cham., Bignoniaceae. Revista Brasileira de Farmacognosia, 19(2B), 592-598.

Cefali, L. C.; Ataide, J. A.; Fernandes, A. R.; Sanchez-Lopez, E.; Sousa, I. M. O.; Figueiredo, M. C.; Ruiz, A. L. T. G.; Foglio, M. A.; Mazzola, P. G. \& Souto, E. B. (2019). Evaluation of in vitro solar protection factor (SPF), antioxidant activity, and cell viability of mixed vegetable extracts from Dirmophandra mollis Benth, Ginkgo biloba L., Ruta graveolens L., and Vitis vinífera L. Plants, 8(11), 453.

Chouksey, D.; Upmanyu, N. \& Pawar, R. S. (2013). Central nervous system activity of Illicium verum fruit extracts. Asian Pacific Journal of Tropical Medicine, 6(11), 869-875.

CNCFlora. Lychnophora pinaster. Lista Vermelha da flora brasileira versão 2012.2 Centro Nacional de Conservação da Flora. Disponível em: http://cncflora.jbrj.gov.br/portal/pt-br/profile/Lychnophora pinaster.Acesso em 5 dez. 2021.

Cruces, I. L.; Patelli, T. H. C.; Tashima, C. M. \& Mello-Peixoto, E. C. T. (2013). Plantas medicinais no controle de urolitíase. Revista Brasileira de Plantas Medicinais, 15(4, suppl 1), 780-788

Cui, J.; Zeng, S. \& Zhang, C. (2022). Anti-hyperglycemic effects of Burdock (Arctium lappa L.) leaf flavonoids through inhibiting $\alpha$-amylase and $\alpha$-glucosidase. International Journal of Food Science \& Technology, 57(1), 541-551.

Das, S. (2020). Natural therapeutics for urinary tract infections - a review. Future Journal of Pharmaceutical Sciences, 6(1), 64.

Daisy, P.; Rayan N. A. \& Rajathi, D. (2007). Hypoglycemic and other related effects of Elephantopus scaber extracts on alloxan induced diabetic rats. Journal of Biological Sciences, 7(2), 433-437.

Dias, M. M.; Zuza, O.; Riani, L. R.; Faria Pinto, P.; Pinto, P. L. S.; Silva, M. P.; Moraes, J.; Ataíde, A. C. Z.; Oliveira Silva, F.; Cecilio, A. B. \& Silva Filho, A. A. (2017). In vitro schistosomicidal and antiviral activities of Arctium lappa L. (Asteraceae) against Schistosoma mansoni and herpes simplex virus-1. Biomedicine \& Pharmacotherapy, 94, 489-498.

Elango, C. \& Devaraj, S. N. (2010). Immunomodulatory effect of Hawthorn extract in an experimental stroke model. Journal of Neuroinflammation, 7(1), 97.

Elekofehinti, O. O.; Onunkun, A. T. \& Olaleye T. M. (2020). Cymbopogon citratus (DC.) Stapf mitigates ER-stress induced by streptozotocin in rats via down-regulation of GRP78 and up-regulation of Nrf2 signaling. Journal of Ethnopharmacology, 262, 113130.

El-Ghorab, A.; El-Massry, K. F. \& Shibamoto, T. (2007). Chemical composition of the volatile extract and antioxidant activities of the volatile and nonvolatile extracts of Egyptian Corn Silk (Zea mays L.). Journal of Agricultural and Food Chemistry, 55(22), 9124-9127.

Erkan, N.; Ayaranci, G. \& Ayaranci, E. (2008). Antioxidant activities of rosemary (Rosmarinus officinalis L.) extract, blackseed (Nigella sativa L.) essential oil, carnosic acid, rosmarinic acid and sesamol. Food Chemistry, 110(1), 76-82. 
Farid, A.; Kamel, D.; Abdelwahab Montaser, S.; Mohamed Ahmed, M.; El Amir, M. \& El Amir, A. (2020). Synergetic role of senna and fennel extracts as antioxidant, anti-inflammatory and anti-mutagenic agents in irradiated human blood lymphocyte cultures. Journal of Radiation Research and Applied Sciences, 13(1), 191-199.

Feriani, A.; Tir, M.; Hamed, M.; Sila, A.; Nahdi, S.; Alwasel, S.; Harrath, A. H. \& Tlili, N. (2020). Multidirectional insights on polysaccharides from Schinus terebinthifolius and Schinusmolle fruits: physicochemical and functional profiles, in vitro antioxidant, anti-genotoxicity, antidiabetic, and antihemolytic capacities, and in vivo anti-inflammatory and anti-nociceptive properties. International Journal of Biological Macromolecules, 165 (Pt B), $2576-2587$.

Fernández, J.; Lagos, P.; Riviera, P. \& Zamorano-Ponce, E. (2009). Effect of boldo (Peumus boldus Molina) infusion on lipoperoxidation induced by cisplatin in mice liver. Phytotherapy Research, 23(7), 1024-1027.

Ferrante, C.; Chiavaroli, A.; Angelini, P.; Venanzoni, R.; Flores, G. A.; Brunetti, L.; Petrucci, M.; Politi, M.; Menghini, L., Leone, S.; Recinella, L.; Gokhan, Z.; Ak, G.; Mascio, M.; Bacchin, F. \& Orlando, G. (2020). Phenolic content and antimicrobial and anti-inflammatory effects of Solidago virga-aurea, Phyllanthus niruri, Epilobium angustifolium, Peumus boldus, and Ononis spinosa Extracts. Antibiotics, 9(11), 783-804.

Ferreira, S. A.; Guimarães, A. G.; Ferrari, F. C.; Carneiro, C. M.; Paiva, N. C. N. \& Guimarães, D. A. S. (2014). Assessment of acute toxicity of the ethanolic extract of Lychnophora pinaster (Brazilian arnica). Revista Brasileira de Farmacognosia, 24(5), 553-560.

Ghowsi, M.; Yousofvand, N. \& Moradi S. (2020). Effects of Salvia officinalis L. (common sage) leaves tea on insulin resistance, lipid profile, andoxidative stress in rats with polycysticovary: An experimental study. Avicenna Journal of Phytomedicine, 10(3), 263-272.

Gonçalves, N. M. T.; Gerenutti, M.; Chaves, D. S. A. \& Vila, M. M. D. C. (2011). A tradição popular como ferramenta para a implantação da Fitoterapia no município de Volta Redonda, RJ. Revista Brasileira de Farmacognosia, 92(4), 346-351.

Google Mapas (2022). Município de Resende, RJ. Disponível em: https://www.google.com.br/maps/place/Resende,+RJ/@-22.4648432,44.4811504,7747m/data=!3m1!1e3!4m5!3m4!1s0x9e778dd541f595:0x3823b6f49a15df81!8m2!3d-22.4722561!4d-44.4649211. Acesso em 17 jan. 2022.

Hacke, A. C. M.; Miyoshi, E.; Marques, J. A. \& Pereira, R. P. (2020). Anxiolytic properties of Cymbopogon citratus (DC.) stapf extract, essential oil and its constituents in zebrafish (Danio rerio). Journal of Ethnopharmacology, 260, 113036.

Hacke, A. C. M.; Miyoshi, E.; Marques, J. A. \& Pereira, R. P. (2021). Cymbopogon citratus (DC.) Stapf, citral and geraniol exhibit anticonvulsant and neuroprotective effects in pentylenetetrazole-induced seizures in zebrafish. Journal of Ethnopharmacology, $275,114142$.

Hajhashemi, V.; Ghannadi, A. \& Sharif, B. (2003). Anti-inflammatory and analgesic properties of the leaf extracts and essential oil of Lavandula angustifolia Mill. Journal of Ethnopharmacology, 89(1), 67-71.

Han, Y.; Li, X.; Zhang, X.; Gao, Y.; Qi, R.; Cai, R. \& Qi, Y. (2020). Isodeoxyelephantopin, a sesquiterpene lactone from Elephantopus scaber Linn., inhibits pro-inflammatory mediators' production through both NF- $\mathrm{BB}$ and AP-1 pathways in LPS-activated macrophages. Internacional Immunopharmacology, 84, 106528.

Heymanns, A. C.; Albano, M. N.; Silveira, M. R.; Muller, S. D.; Petronilho, F. C.; Gainski, L. D.; Cargnin-Ferreira, E. \& Piovezan, A. P. (2021). Macroscopic, biochemical and hystological evaluation of topical anti-inflammatory activity of Casearia sylvestris (Flacourtiaceae) in mice. Journal of Ethnopharmacology, $264,113139$.

Hui, L.; He, L.; Huan, L.; Lan, L. X. \& AiGuo, Z. (2010). Chemical composition of lavender essential oil and its antioxidant activity and inhibition against rhinitis related bacteria. African Journal of Microbiology Research, 4(4), 309-313.

Iannitti, T.; Morales-Medina, J. C.; Bellavite, P.; Rottigni, V. \& Palmieri, B. (2016). Effectiveness and safety of Arnica montana in post-surgical setting, pain and inflammation. American Journal of Therapeutics, 23(1), e184-e197.

Instituto Brasileiro de Geografia e Estatística - IBGE, 2017. Cidades - Resende. Disponível em: https://cidades.ibge.gov.br/brasil/rj/resende/panorama. Acesso em 5 dez. 2021.

Instituto Nacional do Ambiente - INEA. Parque Estadual da Pedra Selada. Disponível em: http://www.inea.rj.gov.br/Portal/Agendas/BIODIVERSIDADEEAREASPROTEGIDAS/UnidadesdeConservacao/INEA_008422. Acesso em 5 dez. 2021.

Iwamoto, L. H.; Vendramini-Costa, D. B.; Monteiro, P. A.; Ruiz, A. L. T. G.; Sousa, I. M. O.; Foglio, M. A.; Carvalho, J. E. \& Rodrigues, R. A. F. K. (2015). Anticancer and anti-inflammatory activities of a standardized dichloromethane extract from Piper umbellatum L. leaves. Evidence-Based Complemenary and Alternative Medicine, 2015.

Jan, N.; Andrabi, K.I. \& John, R. (2017). Calendula officinalis - An important medicinal plant with potential biological properties. Proceedings of the Indian National Science Academy, 83(4),769-787.

Keefea, J. R.; Mao, J. J.; Soeller, I.; Li, Q. S. \& Amsterdam, J. D. (2016). Short-term open-label chamomile (Matricaria chamomilla L.) therapy of moderate to severe generalized anxiety disorder. Phytomedicine, 23(14), 1699-1705.

Khazaei, H.; Pesce, M.; Patruno, A.; Aneva, I. Y. \& Farzaei, M. H. (2020). Medicinal plants for diabetes associated neurodegenerative diseases: a systematic review of preclinical studies. Phytotherapy Research, 35(4), 1697-1718.

Knipping, K.; Esch, E. C. A. M.; Wijering, S. C.; Heide, S.; Dubois, A. E. \& Garssen, J. (2008). In vitro and in vivo anti-allergic effects of Arctium lappa L. Experimental Biology and Medicine, 233(11),1469-1477.

Koubaa, F. G.; Chaâbane, M.; Choura, B.; Turki, M.; Makni-Ayadi, F. \& El Feki, A. (2020). Hepatoprotective effects of Taraxacum officinale root extract on permethrin-induced liver toxicity in adult mice. Pharmaceutical and Biomedical Reserach, 6(3), 223-236. 
Kreis, W.; Munkert, J. \& Pádua R. M. (2017). Biossíntese de metabólitos primários e secundários. In Simões, C. M. O.; Schenkel, E. P.; Mello, J. C. P.; Petrovick, P. R. (Orgs.), Farmacognosia do produto natural ao medicamento (pp. 147-166). Porto Alegre: Artmed Editora.

Li, L.; Wei, S.; Zhu, T.; Xue, G.; Xu, D.; Wang, W.; Wang, X.; Luo, J. \& Kong, L. (2019). Anti-inflammatory norabietane diterpenoids from the leaves of Salvia officinalis L. Journal of Functional Foods, 54, 154-163.

Lima, J. A.; Costa, T. W. R.; Silva, L. L.; Miranda, A. L. P. \& Pinto, A. C. (2016). Antinociceptive and anti-inflammatory effects of a Geissospermum vellosii stem bark fraction. Anais da Academia Brasileira de Ciências, 88(1), 237-248.

Lima, L. F.; Oliveira, J. O.; Carneiro, J. N. P.; Lima, C. N. F.; Coutinho, H. D. M. \& Morais-Braga, M. F. B. (2021). Ethnobotanical and antimicrobial activities of the Gossypium (Cotton) genus: a review. Journal of Ethnopharmacology, 279, 114363.

Lima, T. C.; Matos, S. S.; Carvalho, T. F.; Silveira-Filho, A. J.; Couto, L. P. S. M.; Quintans-Júnior, L. J.; Quintas, J. S. S.; Silva, A. M. O.; Heimfarth, L.; Passos, F. R. S.; Gandhi, S. R.; Lima, B. S. \& Silva, F. A. (2020). Evidence for the involvement of IL-1 $\beta$ and TNF- $\alpha$ in anti-inflammatory effect and antioxidative stress profile of the standardized dried extract from Miconia albicans Sw. (Triana) leaves (Melastomataceae). Journal of Ethnopharmacology, 259,112908

Lima, T. C. D.; Cardoso, M. V.; Modesto, T.; Oliveira, A. L. B.; Silva, M. N. \& Monteiro, M. C. (2016). Breve revisão etnobotânica, fitoquímica e farmacologia de Stryphnodendron adstringens utilizada na Amazônia. Revista Fitos, 10(3), 329-338.

Lorençone, B. R.; Guarnier, L. P.; Palozi, R. A. C.; Romão, P. V. M.; Marques, A. A. M.; Klider, L. M.; Souza, R. I. C.; Santos, A. C.; Tirloni, C. A. S.; Cassemiro, N. S.; Silva, D. B.; Budel, J. M. \& Junior, A. G. (2021). Atheroprotective properties of Costus spicatus (Jacq.) Sw. in female rats. Life, 11(3), 212233.

Maghsoumi-Norouzabad, L.; Alipoor, B.; Abed, R.; Efteknar Sadat, B.; Mesgari-Abbasi, M. \& AsghariJafarabadi, M. (2016).Effects of Arctium lappa L. (Burdock) root tea on inflammatory status and oxidative stress in patients with knee osteoarthritis. International Journal of Rheumatic Diseases, 19(3), 255261 .

Malfa, G. A.; Di Giacomo, C.; Cardia, L.; Sorbara, E. E.; Mannucci, C. \& Calapai, G. (2021). A standardized extract of Opuntia ficus-indica (L.) Mill and Olea europaea L. improves gastrointestinal discomfort: a double-blinded randomized-controlled study. Phytotherapy Research, 35(7), 3756-3768.

Martinazzo, A. P.; Filho, L. C. C.; Rosa, D. A.; Teodoro, C. E. S. \& Tomazelli, K. K. (2013). Perfil de utilização de Fitoterápicos nos municípios de volta Redonda e Barra Mansa/RJ. Revista Fitos, 8(2), 103-112.

Matsubara, S. \& Rodriguez-Amaya, D. B. (2006). Teores de catequinas e teaflavinas em chás comercializados no Brasil. Ciência e Tecnologia de Alimentos, 26(2), 401-407.

Melo, C. P. B.; Saito, P.; Vale, D. L.; Rodrigues, C. C. A.; Pinto, I. C.; Martinez, R. M.; Bezerra, J. R.; Baracat, M. M.; Verri, W. A.; Fonseca-Bazzo, Y. M.; Georgetti, S. R. \& Casagrande, R. (2021). Protective effect of oral treatment with Cordia verbenacea extract against UVB irradiation deleterious effects in the skin of hairless mouse. Journal of Photochemistry Photobiology B: Biology, 216, 112151.

Mondin, C. A. (2020). Sphagneticola trilobata (L.) Pruski. Flora do Brasil 2020. Jardim Botânico do Rio de Janeiro. Disponível em: http://floradobrasil.jbrj.gov.br/reflora/floradobrasil/FB16304. Acesso em 17 jan. 2022.

Moreno, K. G. T.; Junior, A. G.; Santos, A. C.; Palozi, R. A. C.; Guarnier, L. P.; Marques, A. A. M.; Romão, P. V. M.; Lorençone, B. R.; Cassemiro, N. S.; Silva, D. B.; Tirloni, C. A. S. \& Barros, M. E. (2021). Nephroprotective and antilithiatic activities of Costus spicatus (Jacq.) Sw.: Ethnopharmacological investigation of a species from the Dourados region, Mato Grosso do Sul state, Brazil. Journal of Ethnopharmacology, $266,113409$.

Nascimento, C. A.; Santos, A. C. M.; Silva, D. M.; Barbosa, N. R.; Moura, E. L.; Balliano, T. L.; Figueiredo, E. V. M. S.; Farias, K. F. \& Pitta, G. B. B.(2021). Evidências sobre as propriedades do extrato de Stryphnodendron adstringens (Mart.) Coville (Barbatimão) para a prática clínica. Research, Society and Development, 10(1), e3010111350.

Nascimento, E. L.; Watanabe, M.; Fonseca, C. D.; Schlottfeldt, F. S. \& Vattimo, M. F. F. (2014). Renoprotective effect of the Echinodorus macrophyllus in induced renal injury. Acta Paulista de Enfermagem, 27(1), 12-17.

Neto, J. N.; Coelho, T. M.; Aguiar, G. C.; Carvalho, L. R.; Araújo, A. G. P.; Girão, M. J. B. C. \& Schor, E. (2011). Experimental endometriosis reduction in rats treated with Uncaria tomentosa (cat's claw) extract. European Journal of Obstetrics \& Gynecology and Reproductive Biology, 154(2), 205-208.

Noriega, P.; Ropke, C. D.; Consiglieri, V. O.; Taqueda, M. E. S.; Tavares, L. C.; Wasicky, A.; Bacchi, E. M. \& Barros, S. B. M. (2008). Optimization of Pothomorphe umbellata (L.) Miquel topical formulations using experimental design. International Journal of Pharmaceutics, 353(1), 149-159.

Oliveira, I. S. S.; Colares, A. V.; Cardoso, F. O.; Tellis, C. J. M.; Chagas, M, S. S.; Behrens, M. D.; Calabrese, K. S.; Almeida-Souza, F. \& Abreu-Silva, A. L. (2019). Vernonia polysphaera Baker: anti-inflammatory activity in vivo and inhibitory effect in lps-stimulated raw 264.7 cells. Plos One, 14(12), e0225275.

Oliveira, R. T.; Rolim, C. S. S.; Rolim, L. N.; Sousa, M. L. G.; Martins, G. A. S.; Castro, L. M.; Nascimento, W. M.; Saraiva-Bonatto, E. C.; Numonura, R. C. S.; Lamarão, C. V. \& Zanotto, S. P. (2021). Endopleura uchi - A review about its nutritional compounds, biological activities and production market. Food Research International, 139, 109884.

Oliveira, V. M.; Thomaz, D. V.; Baldoni, F. M. D. C. \& Couto, R. O. (2021). Is the systemic administration of arnica extracts safe? A systematic review of preclinical trials. Research, Society and Development, 10(8), e27110817257.

Otenio, J. C.; Baisch, R. G.; Carneiro, V. P. P.; Lourenço, E. L. B.; Alberton, O. \& Jacomassi, E. (2020). Etnofarmacologia da Cuphea carthagenesis (Jacq.) J. F. Macbr: Uma revisão. Brazilian Journal of Development, 6(3), 10206-10219. 
Otero, C.; Miranda-Rojas, S.; Llancalahuén, F. M.; Fuentes, J. A.; Atala, C.; González-Silva, G.; Verdugo, D.; Sierra-Rosales, P.; Moreno, A. \& GordilhoFuenzalida, F. (2022). Biochemical characterization of Peumus boldus fruits: insights of its antioxidant properties through a theoretical approach. Food Chemistry, 370, 131012.

Owlia, P.; Rasooli, I. \& Saderi, H. (2007). Antistreptococcal and antioxidant activity of essential oil from Matricaria chamomilla L. Research Journal of Biological Sciences, 2(2), 155-160.

Owoyele, B. V.; Negedu, M. N.; Olaniran, S. O.; Onasanwo, S. A.; Sanya, J. O.; Oyeleke, S. A.; Lbidapo, A. J. \& Soladoye, A. O. (2010). Analgesic and antiinflammatory effects of aqueous extract of Zea mays husk in male Wistar rats. Journal of Medicinal Food.,13(2), 343-347.

Parente, C. E. T. \& Rosa, M. M. T. (2001). Plantas comercializadas como medicinais no Município de Barra do Piraí, RJ. Rodriguésia, 52(80), 47-59.

Parente, L. M. L.; Lino Junior, R. S.; Tresvenzol, L. M. F.; Vinaud, M. C.; Paula, J. R. \& Paulo, N. M. (2012). Wound Healing and Anti-Inflammatory Effect in Animal Models of Calendula officinalis L. Growing in Brazil. Evidence-Based Complemenary and Alternative Medicine, $2012,375671$.

Pascoalino, S. D.; Lüdtke, D. D.; Heymanns, A. C.; Salm, D.; Costa, D. M.; Martins, D. F.; Horewicz, V. V.; Bobinski, F. \& Piovezan, A. P. (2020). Antihyperalgesic effect of exercise is augmented by the oral pretreatment with extract of Casearia sylvestris in an animal model of osteoarthritis. Journal of Orthopaedics, Trauma and Rehabilitation, 27(2), 148-156.

Patra, J. K.; Das, G.; Bose, S.; Banerjee, S.; Vishnuprassad, C. N.; Pilar, R. M. \& Shin, H. (2020). Star anise (Illicium verum): Chemical compounds, antiviral properties, and clinical relevance. Phytotherapy Research, 34(6), 1248-1267.

Pereira, O. R.; Catarino, M. D.; Afonso, A. F.; Silva, A. M. S. \& Cardoso, S. M. (2018). Salvia elegans, Salvia greggii and Salvia officinalis decoctions: Antioxidant activities and inhibition of carbohydrate and lipid metabolic enzymes. Molecules, 23(12), 3169.

Pimentel, A. S. G. (2021). Rosmarinus officinalis L. para o tratamento da ansiedade: uma revisão de literatura. Research, Society and Development, 10(11), e285101119635.

Pinheiro, A. C. S.; Pais, A. A.; Tardivo, A. C. B. \& Alves, M. J. Q. F. (2011). Efeito do extrato aquoso de cabelo de milho (Zea mays L.) sobre a excreção renal de água e eletrólitos e pressão arterial em ratos Wistar anestesiados. Revista Brasileira de Plantas Medicinais, 13(4), 375-381.

Portella, V. G.; Conseza, G. P.; Diniz, L. R. L.; Pacheco, L. F.; Cassali, G. D.; Caliari, M. V.; Brandão, M. G. L. \& Vieira, M. A. R. (2012). Nephroprotective effect of Echinodorus macrophyllus Micheli on gentamicin-induced nephrotoxicity in rats. Nephron Extra, 2(1), $177-183$.

Quezada, N.; Asensio, M.; Del Valle, J. M.; Aguilera, J. M. \& Gómez, B. (2006). Antioxidant activity of crude extract, alkaloid fraction, and flavonoid fraction from Boldo (Peumus boldus Molina) leaves. Journalof Food Science, 69(5), 371-376.

Quintans-Junior, L. J.; Gandhi, S. R.; Passos, F. R. S.; Heimfarth, L.; Pereira, E. W. M.; Monteiro, B. S.; Santos, K. S.; Duarte, M. C.; Abreu, L. S.; Nascimento, Y. M.; Tavares, J. F.; Silva, M. S.; Menezes, I. R. A.; Coutinho, H. D. M.; Lima, A. A. N.; Zengin, G. \& Quintans, J. S. S. (2020). Dereplication and quantification of the ethanol extract of Miconia albicans (Melastomaceae) by HPLC-DAD-ESI-/MS/MS, and assessment of its anti-hyperalgesic and antiinflammatory profiles in a micearthritis-like model: evidence for involvement of TNF- $\alpha$, IL-1 $\beta$ and IL-6. Journal of Ethnopharmacology, $258,112938$.

Rahimi, H. M.; Khosravi, M.; Hesari, Z.; Sharifdini, M.; Mirjalali, H. \& Zali, M. R. (2020). Anti-toxoplasma activity and chemical compositions of aquatic extract of Mentha pulegium L. and Rubus idaeus L.: an in vitro study. Food Science \& Nutrition, 8(7), 3656-3664.

Raji, Y. \& Oloyede, G. K. (2012). Antiulcerogenic effects and possible mechanism of action of Quassia amara (L. Simaroubaceae) extract and its bioactive principle in rats. African Journal of Traditional, Complementary and Alternative Medicines, 9(1), 112-119.

Rambo, D. F.; Biegelmeyer, R.; Toson, N. S. B.; Dresch, R. R.; Moreno, P. R. H. \& Henriques, A. T. (2019a). Box-Behnken experimental design for extraction optimization of alkaloids from Erythrina verna Vell. Trunk barks and LC method validation. Industrial Crops and Products, $133,250-258$.

Rambo, D. F.; Biegelmeyer, R.; Toson, N. S. B.; Dresch, R. R.; Moreno, P. R. H. \& Henriques, A. T. (2019b). The genus Erythrina L.: a review on its alkaloids, preclinical, and clinical studies. Phytotherapy Research, 33(5), 1258-1276.

Rana, M. G.; Katbamna, R. V.; Padhya, A. A.; Dudhrejiya, A. D.; Jivani, N. P. \& Sheth, N. R. (2010). In vitro antioxidant and free radical scavenging studies of alcoholic extract of Medicago sativa L. Romanian Journal of Biology-Plant Biology, 55(1), 15-22.

RENISUS. (2009). Relação Nacional de Plantas Medicinais de Interesse ao SUS. Ministério da Saúde. Disponível em: http://portal.saude.gov.br/portal/arquivos/pdf/RENISUS.pdf. Acesso em 5 dez. 2021.

Revilla, J. (2002). Plantas da Amazônia - Oportunidades Econômicas e Sustentáveis; Manaus: INPA.

Roby, M. H. H.; Sharhan, M. A.; Selim, K. A. H. \& Khalel, I. K. (2013). Antioxidant and antimicrobial activities of essential oil and extracts of fennel (Foeniculum vulgare L.) and chamomile (Matricaria chamomilla L.). Industrial Crops and Products, 44, 437-445.

Rodrigues, E. L.; Marcelino, G.; Silva, G. T.; Figueiredo, P. S.; Garcez, W. S.; Corsino, J.; Guimarães, R. C. A. \& Freitas, K. C. (2019). Nutraceutical and medicinal potential of the Morus species in metabolic dysfunctions. International Journal of Molecular Sciences, 20 (2), 301.

Rodrigues, S. O.; Vieira, A. L. S. M.; Barros, N. B. \& Oliveira, C. A. B. (2021). Phytotherapy as an alternative in the treatment of menopause symptoms. Brazilian Journal of Development, 7(4), 38529-38542.

Saeed, M.; Naveed, M.; Arif, M.; Kakar, M. U.; Manzoor, R.; Abd EL-Hack, M. E.; Alagawany, M.; Tiwari, R.; Khandia, R.; Munjal, A.; Karthik, K.; Dhama, K.; Iqbal, H. M. N.; Dadar, M. \& Sun, C. (2017). Green tea (Camellia sinensis) and 1-theanine: medicinal values and beneficial applications in humans: Acomprehensive review. Biomedicine \& Pharmacotherapy, 95, 1260-1275. 
Santana, L. C. L. R.; Brito, M. R. M.; Oliveira, G. L. S.; Citó, A. M. G. L.; Alves, C. Q.; David, J. M. \& Freitas, R. M. (2014). Mikania glomerata: Phytochemical, pharmacological, and neurochemical study. Evidence-Based Complemenary and Alternative Medicine, $2014,710410$.

Santos, A. R. F. C.; Cruz, J. H. A.; Guênes, G. M. T.; Oliveira Filho, A. A. \& Alves, M. A. S. G. (2019). Matricaria chamomilla L: propriedades farmacológicas. Archives of Health Investigation, 8(12), 846-852.

Santos, M. C.; Toson, N. S. B.; Pimentel, M. C. B.; Bordignon, S. A. L.; Mendez, A. S. L. \& Henriques, A. T. (2020). Polyphenols composition from leaves of Cuphea spp. and inhibitor potential, in vitro, of angiotensin I-converting enzyme (ACE). Journal of Ethnopharmacology, $255,112781$.

Santos-Oliveira, R.; Coulaud-Cunha, S. \& Colaço W. (2009). Revisão da Maytenus ilicifolia Mart. ex Reissek, Celastraceae. Contribuição ao estudo das propriedades farmacológicas. Revista Brasileira de Farmacognosia, 19(2b), 650-659.

Santos, R. I. (2004). Metabolsimo primário e origem de metabólitos secundários. In Simões, C. M. O.; Schenkel, E. P.; Gosmann, G.; Mello, J. C. P.; Mentz, L. A.; Petrovick, P. R. (Orgs.) Farmacognosia da planta ao medicamento. (pp. 403-434) Porto Alegre/Florianópolis: Editora da UFRGS/ Editora da UFSC.

Savych, A.; Bilyk, O.; Vaschuk, V. \& Humeniuk, L. (2021). Analysis of inulin and fructans in Taraxacum officinale L. roots the main inulin-containing component of antidiabetic herbal mixture. Pharmacia, 68(3), 527-532.

Schaedler, M. I.; Palozi, R. A. C.; Tirloni, C. A. S.; Silva, A. O.; Araújo, V. O.; Lourenço, E. L. B.; Souza, L. M.; Lívero, F. A. R. \& Gasparotto Junior, A. (2018). Redox regulation and NO/cGMP plus K+ channel activation contributes to cardiorenal protection induced by Cuphea carthagenensis (Jacq.) J.F. Macbr. in ovariectomized hypertensive rats. Phytomedicine, 51, 7-19.

Schindler, M. S. Z.; Calisto, J. F. F.; Marins, K.; Regginato, A.; Mezzomo, H.; Zanatta, A. P.; Radunz, A. L.; Mariot, M. P.; Dal Magro, J. \& Zanatta, L. (2021). Characterization of the chemical profile and the effects of ethanolic extracts of Maytenus ilicifolia Mart. ex Reissek on glucose metabolism in normal hyperglycemic rats. Journal of Ethnopharmacology, 276, 114173.

Senger, A. E. V.; Schwanke, C. H. A. \& Gottlieb, M. G. V. (2010). Chá verde (Camellia sinensis) e suas propriedades funcionais nas doenças crônicas não transmissíveis. Scientia Medica, 20(4), 292-300.

Serra, M. B.; Barroso, W. A.; Rocha, C.; Furtado, P. G. R.; Borges, A. C. R.; Silva, S. N.; Tangerina, M. M. P.; Nascimento, J. R.; Vilegas, W.; Alves, A. C.; Barbeiro, D. F.; Souza, H. P.; Abreu, I. C.; Brges, M. O. R. \& Gonçalves, R. V. (2020). Chemical characterization and wound healing property of Jacaranda decurrens Cham. (Bignoniaceae): an experimental study based on molecular mechanisms. Evidence-Based Complemenary and Alternative Medicine, 2020, 4749712 .

Seyedjavadi, S. S.; Khani, S.; Zare-Zardini, H.; Halabian, R.; Goudarzi, M.; Khatami, S.; Fooladi, I. A. A.; Amani, J. \& Razzaghi-Abyaneh, M. (2019). Isolation, functional characterization, and biological properties of MCh- AMP1, a novel antifungal peptide from Matricaria chamomilla L. Chemical Biology \& Drug Design, 93(5), 949-959.

Sheikhani, A.; Kholdi, N. \& Mokhtari, M. (2017). An overview of the most effective tranquilizer herbs.Journal of Basic and Clinical Pathophysiology, 5(2), 27-34.

Shen, X.; Guo, M.; Yu, H.; Liu, D.; Lu, Z. \& Lu, Y. (2019). Propionibacterium acnes related anti-inflammation and skin hydration activities of madecassoside, a pentacyclic triterpene saponin from Centella asiatica. Bioscience, Biotechnology, and Biochemistry, 83(3), 561-568.

Silva, A. M.; Paes, L. W. C.; Martinazzo, A. P.; Souza, P. P. \& Martins, F. A. C. B. (2021). Plantas medicinais como recurso terapêutico nos bairros Siderópolis e Santa Rita do Zarur em Volta Redonda/RJ. Brazilian Journal of Development, 7(2), 11997-12014.

Silva, C. J.; Bastos, J. K. \& Takahashi, C. S. (2010). Evaluation of the genotoxic and cytotoxic effects of crude extracts of Cordia ecalyculata and Echinodorusgrandiflorus. Journal of Ethnopharmacology, 127(2), 445-450.

Silva, G. P.; Fernandes, D. C.; Vigliano, M. V.; Fonseca, E. N.; Santos, S. V. M.; Marques, P. V.; Justo, M. G.; Sabino, K. C. C. \& Coelho, M. G. P. (2016). Flavonoid-enriched fraction from Echinodorusmacrophyllus aqueous extract exhibits high in-vitro and in-vivo anti-inflammatory activity. Journal of Pharmacy and Pharmacology, 68(12), 1584-1596.

Silva-López, R. E. \& Santos, B. C. (2015). Bauhinia forficata Link (Fabaceae). Revista Fitos, 9(3), $217-232$.

Silva, M. V. S.; Padilha, R. T. \& Padilha, D. M. M. (2021). Benefícios da Moringa oleifera para saúde humana e animal: Revisão de Literatura. Research, Society and Development., 10(8), e50010817495.

Soheili, M. \& Salami, M. (2019). Lavandula angustifolia biological characteristics: an in vitro study. Journal of Cellular Physiology, 234(9), 16424-16430.

Sombra, A. C. (2016). Arranjo Produtivo Local - Volta Redonda, uma abordagem regional sobre os aspectos etnobotânicos, agroecológicos e serviços relacionados à Fitoterapia. Revista Fitos, 10(4), 14-20.

Spósito, L.; Oda, F. B.; Vieira, J. H.; Carvalho, F. A.; Ramos, M. A. S.; Castro, R. C.; Crevelin, E. J.; Crotti, A. E. M.; Santos, A. G.; Silva, P. B.; Chorilli, M. \& Bauab, T. M. (2019). In vitro and in vivo anti-Helicobacter pylori activity of Casearia sylvestris leaf derivatives. Journal of Ethnopharmacology, 233, 112 .

Swapna, K.; Uddandrao, V. V. S.; Parim, B.; Ravindarnaik, R.; Suresh, P.; Ponnusamy, P.; Balakrishnan, S.; Vadivukkarasi, S.; Harishankar, N.; Reddy, K. P.; Nivedla, P. R. \& Saravanan, G. (2019). Effects of asiatic acid, an active constituent in Centella asiatica (L.): restorative perspectives of streptozotocinnicotinamide induced changes on lipid profile and lipid metabolic enzymes in diabetic rats. Comparative Clinical Pathology, 28, $1321-1329$.

Tang, L.; Li, X.; Wa, L.; Xiao, Y.; Zeng, X. \& Ding, H. (2019). Herbal medicines for irinotecan-induced diarrhea. Frontiers in Pharmacology, 10, 182. 
Research, Society and Development, v. 11, n. 2, e15211225423, 2022

(CC BY 4.0) | ISSN 2525-3409 | DOI: http://dx.doi.org/10.33448/rsd-v11i2.25423

Temponi, V. S.; Silva, J. B.; Alves, M. S.; Ribeiro, A.; Pinho, J. J. R. G.; Yamamoto, C. H.; Pinto, M. A. O.; Del-Vechio-Vieira, G. \& Sousa, O. V. (2012). Antinociceptive and anti-inflammatory effects of ethanol extract from Vernonia polyanthes leaves in rodents. International Journal of Molecular Sciences, 13(3), 3887-3899.

Trang, D. T.; Hoang, T. K.; Nguyen, T. T. M.; Cuong, P.; Dang, N. H.; Dang, H. D.; Quang, T. N. \& Dat, N. T. (2020). Essential oils of lemongrass (Cymbopogon citratus Stapf) induces apoptosis and cell cycle arrest in A549 lung cancer cells. BioMed Research International., $2020,1-8$.

Tung, Y. T.; Wu, M. F.; Lee, M. C.; Wu, J. H.; Huang, C. C. \& Huang, W. C. (2019). Antifatigue activity and exercise performance of phenolic-rich extracts from Calendula officinalis, Ribes nigrum, and Vaccinium myrtillus. Nutrients, 11(8), 1715.

Uliana, M. P.; Fronza, M.; Silva, G. A.; Vargas, T. S.; Andrade, T. U. \& Scherer, R. (2016). Composition and biological activity of Brazilian rose pepper (Schinus terebinthifolius Raddi) leaves. Industrial Crops and Products, 83, 235-240.

Valverde, S. V.; Oliveira, T. B. \& Souza, S. P. (2012). Solidago chilensis Meyen (Asteraceae). Revista Fitos, 7(3), $131-136$.

World Health Organization. (1998). Bulletin of the World Health Organization. Regulatory situation of herbal medicines. A worldwide review. Disponível em: https://apps.who.int/iris/handle/10665/63801. Acesso em 5 dez. 2021.

Yao, C. H.; Yeh, J. Y.; Chen, Y. S.; Li, M. H. \& Huang, C. H. (2017). Wound-healing effect of electrospun gelatin nanofibres containing Centella asiática extract in a rat model. Journal of Tissue Engineering and Regenerative Medicine, 11(3), 905-915.

Zoofishan, Z.; Kúsz, N.; Csorba, A.; Tóth, G.; Hajagos-Tóth, J.; Kothencz, A.; Gáspár, R. \& Hunyadi, A. (2019). Antispasmodic activity of prenylated phenolic compounds from the root bark of Morus nigra. Molecules, 24(13), 2497. 